Las zonas económicas especiales en el suroeste de México y el desarrollo regional José Manuel Orozco Plascencia

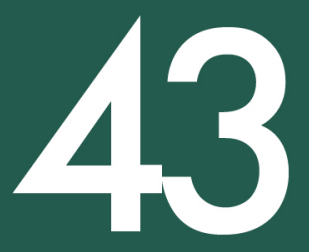

ENERO/FEBRERO 2018

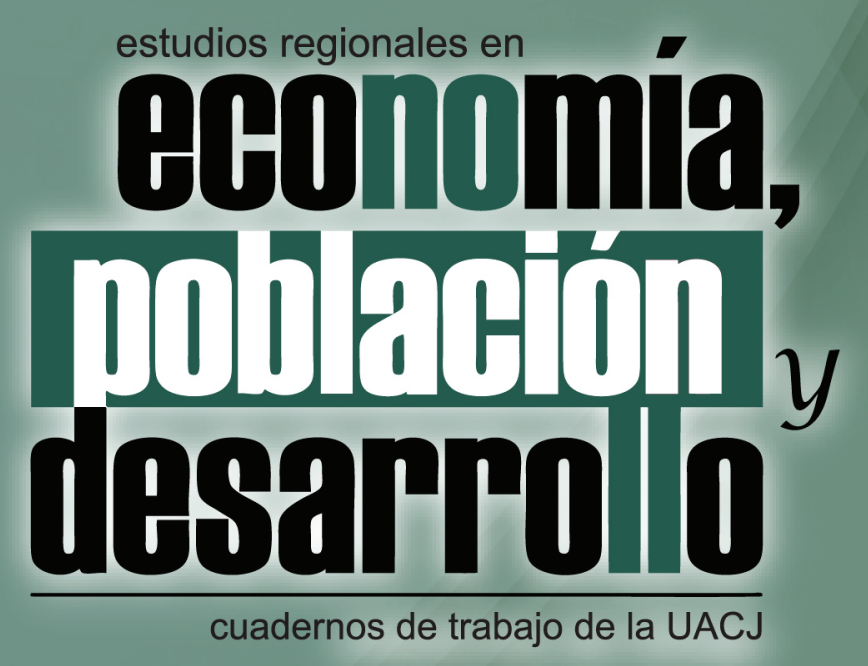




\title{
Las zonas económicas especiales en el suroeste de México y el desarrollo regional
}

\author{
José Manuel Orozco Plascencia
}

UNIVERSIDAD AUTÓNOMA DE CIUDAD JUÁREZ 


\title{
UNIVERSIDAD AUTÓNOMA DE CIUDAD JUÁREZ \\ Instituto de Ciencias Sociales y Administración
}

\author{
Cuerpo Académico de Estudios Regionales en \\ Economía, Población y Desarrollo
}

Lic. Ricardo Duarte Jáquez

Rector

M.C. David Ramírez Perea

Secretario General

Mtro. Juan Ignacio Camargo Nassar

Director del Instituto de Ciencias

Sociales y Administración

Mtro. Ramón Chavira Chavira

Director General de Difusión

Cultura y Divulgación Científica

Dr. Luis Enrique Gutiérrez Casas

Coordinador General de

Investigación y Posgrado

\section{Dr. Jaime Alberto Arellano Quiroga \\ Coordinador del Cuerpo Académico de \\ Estudios Regionales en Economía, Población y Desarrollo}

Director y editor

Dr. Luis Enrique Gutiérrez Casas

Comité editorial

Sección internacional

Dra. Sofía Boza Martínez (Universidad de Chile, Chile)

Dra. Olga Biosca Artiñano (Glasgow Caledonian

University, Reino Unido)

Dra. Ángeles Sánchez Díez (Universidad Autónoma de

Madrid, España)

Dr. Thomas Fullerton Mankin (University of Texas at

E1 Paso, Estados Unidos)

Dr. Adrián Rodríguez Miranda (Universidad de la

República, Uruguay)

Sección local

(Universidad Autónoma de Ciudad Juárez)

Dra. Myrna Limas Hernández

Dra. Ikuho Kochi

Dr. Raúl Alberto Ponce Rodríguez

Dr. Isaac Leobardo Sánchez Juárez

Dr. Héctor Alonso Barajas Bustillos

Diseño de cubierta Abigail Bautista
Estudios Regionales en Economía, Población

y Desarrollo. Cuadernos de Trabajo de la UACJ

ISSN 2007-3739

Número 43. Enero/Febrero 2018

Las zonas económicas especiales en el suroeste de

México y el desarrollo regional

José Manuel Orozco Plascencia

Universidad Autónoma de Ciudad Juárez

Estudios Regionales en Economía, Población y Desarrollo. Cuadernos de Trabajo de la UACJ

Año 8, No. 43 enero - febrero 2018, es una publicación bimestral editada por la Universidad Autónoma de Ciudad Juárez a través del Cuerpo Académico de Estudios Regionales en Economía, Población y Desarrollo del Instituto de Ciencias Sociales y Administración. Redacción: Avenida Universidad y H. Colegio Militar, Zona Chamizal s/n., C.P. 32300, Ciudad Juárez, Chihuahua, México. Teléfonos: (656) 688-38-00, ext. 3792. Correo electrónico: lgtz@uacj.mx.

Editor responsable: Luis Enrique Gutiérrez Casas. Reserva de derechos al uso exclusivo No. 04-2011-021713353900-102. ISSN 2007-3739, Impresa por Studio Los Dorados, calle Del Campanario, número 820-2, Santa Cecilia, C.P. 32350, Cd. Juárez, Chihuahua. Distribuidor: Subdirección de Gestión de Proyecto y Marketing Editorial. Ave. Plutarco Elías Calles 1210, Foviste Chamizal, C.P. 32310, Ciudad Juárez, Chihuahua. Este número se terminó de imprimir el 15 de diciembre, 2017 con un tiraje de 120 ejemplares.

Los ensayos publicados son responsabilidad exclusiva de sus autores. Se autoriza la reproducción total o parcial bajo condición de citar la fuente.

\section{Registrada en:}

Publicación afiliada a la Red Iberoamericana de Estudios del Desarrollo

Universidad Autónoma de Ciudad Juárez

Ave Plutarco Elías Calles 1210

Foviste Chamizal, C.P. 32310

Ciudad Juárez, Chihuahua, México

www.uacj.mx

(C) Universidad Autónoma de Ciudad Juárez 


\title{
Las zonas económicas especiales en el suroeste de México y el desarrollo regional
}

\author{
José Manuel Orozco Plascencia*
}

\begin{abstract}
Resumen
En 2016, el congreso mexicano decretó la creación de cuatro Zonas Económicas Especiales (ZEE) en los puertos de Lázaro Cárdenas, Michoacán, Puerto Chiapas, Chiapas, Salina Cruz, Oaxaca, y Coatzacoalcos, Veracruz, cuya transferencia de recursos no será suficiente para superar en el largo plazo la difícil situación socioeconómica de marginación y pobreza que prevalece en la región suroeste de México. En este texto se analizan las ZEE mediante la comparación de información, acciones, beneficios económico-fiscales promovidos por el sector gubernamental y el impacto de dicha política pública para el desarrollo regional. Para una mayor compresión del funcionamiento de las ZEE en México y el mundo, se describirá la experiencia rescatada en 30 años de estudio por el Banco Mundial (BM), particularmente aquella promovida en países asiáticos donde se concentra $90 \%$ del empleo de las ZEE.
\end{abstract}

Palabras clave: Zonas económicas, beneficios fiscales, pobreza, marginación.

\begin{abstract}
During 2016 the Mexican Congress decreed the creation of four Special Economic Zones (SEZ), located Southern Mexico: Lázaro Cárdenas, Michoacán; Puerto Chiapas, Chiapas; Salina Cruz, Oaxaca; y Coatzacoalcos, Veracruz, however, this resource's transfer will not be enough in order to overcome the region economic situation, which has been precarious for a long term, as well as the marginalization and poverty situation. This text analyzes the Special Economic Areas through the comparison of information, actions and fiscal-economic benefits driven by the public sector, as well as the regional development impacts of the public policy. For a better comprehension of how a SEZ works in Mexico and worldwide, it will be described the World Bank study based on a 30 year period of observation, particularly the experienced observed in Asian countries, which concentrate $90 \%$ of SEZ employment.
\end{abstract}

Keywords: Economic zones, tax and subsidies, poverty, marginalization.

JEL Classification: R11, R58, I38.

- Recibido en: Septiembre de 2017.

- Aprobado en: Noviembre de 2017.

Profesor-investigador de la Facultad de Economía de la Universidad de Colima. La línea de investigación que desarrolla es sobre competitividad y desarrollo regional.Correo electrónico: manuel_orozco@ucol.mx. 


\section{$\rightarrow$ 1. Introducción.}

Uno de los componentes de mayor potencial para contribuir a un comportamiento favorable de la economía en su conjunto, es la promoción e implementación de políticas públicas vinculadas al desarrollo regional. Para el caso de México, desde la década de 1970 se han registrado esfuerzos gubernamentales, que han buscado generar condiciones adecuadas en el espacio económico territorial del país, destacando la puesta en marcha de proyectos regionales como los centros turísticos integralmente planeados, polos de desarrollo, programas integrales de desarrollo rural, zonas y distritos industriales, cluster o conglomerados agroindustriales y manufactureros, el Plan Puebla Panamá, la Escalera Náutica, los Pueblos Mágicos, entre otros.

En la actualidad sobresale la estrategia gubernamental de crear cuatro ZEE para incidir en la mejora de las condiciones de desarrollo del suroeste mexicano, cuya ubicación geográfica será en los Puertos de Lázaro Cárdenas, Michoacán; Puerto Chiapas, Tapachula, Chiapas; y el Corredor Interoceánico Salina Cruz, Oaxaca y Coatzacoalcos, Veracruz (Presidencia de la República, 2016). Dicha propuesta se convirtió en la Ley de ZEE aprobada por el Congreso de la Unión el 1 de junio 2016, con el objeto de impulsar el crecimiento económico sostenible, reducir la pobreza, proveer de servicios básicos y expandir de oportunidades para vidas saludables y productivas, en las regiones del país que tengan mayores rezagos en desarrollo social, a través del fomento de la inversión, la productividad, la competitividad, el empleo y una mejor distribución del ingreso entre la población (LXII Legislatura de la Cámara de Diputados, 2016).

Según Gutiérrez Candiani (2016) la realidad del sureste de México no es un problema aislado; ya que es una situación que requiere atención de toda la sociedad, incluyendo empresarios, cuya participación será primordial en el proyecto de ZEE, ya que en cinco años se generarán 6 mil empleos, se atraerá una Inversión Extranjera Directa (IED) de 6 mil millones dólares en el mismo periodo; y de 27 mil millones de dólares en 10 años.

De acuerdo con Abraham Zamora Torres, Director General del Banco Nacional de Obras y Servicios Públicos S.N.C (Banobras), las ZEE son un mecanismo efectivo para detonar el desarrollo regional, y permitirán acelerar el crecimiento industrial del sur del país. De igual forma, representan un cambio en la estrategia para abatir el rezago de los estados más pobres, pues buscan generar riqueza en y para estas regiones, atrayendo inversiones productivas que creen fuentes de ingreso para la población.

Sin embargo, al revisar cifras de la región en el periodo 1990-2015, se detectó un porcentaje alto de población rural e indígena, con baja participación en el Producto Interno Bruto (PIB) nacional y de atracción de IED, del 10.7 y $8 \%$, respectivamente; un PIB per cápita e ingreso corriente por debajo del promedio nacional, una concentración de niveles superiores al $60 \%$ de pobreza en 
sus estados, destacando el caso de Chiapas con 76.2\%, además de casi el 50\% de la pobreza extrema. De 1990 a 2015 se mantuvo un alto índice de marginación en Chiapas al pasar de primer a segundo lugar, Oaxaca permanece en el tercer sitio y Veracruz en cuarto, solo Michoacán bajo del lugar 8 al 14. Dichas entidades registran un Coeficiente de Gini (CG) cercano al 50\% y un Índice de Desarrollo Humano (IDH) promedio de 0.70.

En el Plan Nacional de Desarrollo (PND 2013-2018) se reconoce que las profundas diferencias observadas tienen un claro componente geográfico, pues la productividad tiende a ser menor en las entidades federativas del sur del país. Un elemento que explica las marcadas brechas entre las entidades federativas, es la estrecha correlación que existe entre informalidad y baja productividad a nivel estatal

En ese contexto, para revisar si la gestión pública será suficiente para disminuir la problemática regional en el marco de las ZEE, el objetivo de la presente investigación consistirá en analizar la información discursiva y las acciones que emanan del sector público-privado para promover la puesta en marcha de las ZEE y contrastarla con la situación socioeconómica, de pobreza, pobreza extrema y marginación que prevalece en la región para efectos de determinar las perspectivas de éxito o fracaso de las misma.

En la hipótesis que sustenta el presente estudio, se establece que "la transferencia de beneficios hacia las ZEE no será suficiente para superar, en el corto, mediano y largo plazo, la difícil situación socioeconómica que enfrenta la región suroeste de México, la cual está sustentada en altos grados de pobreza y marginación desde la década de 1990".

La hipótesis planteada permite inferir que existen dos perspectivas o posicionamientos diferentes con relación a los beneficios que podrían generar las ZEE. Por una lado, el Centro de Estudios de las Finanzas Públicas (CEFP, 2016) del Congreso de la Unión describe que las ZEE tendrán un efecto positivo traducido en beneficios fiscales y económicos para las empresas, con el objeto de incentivar la generación de empleos permanentes e inversión productiva, que impulse el desarrollo económico y la creación de infraestructura, entre los que destacan: mejores condiciones de financiamiento y un régimen aduanero especial. Las ZEE contarán con financiamiento preferencial de la banca de desarrollo, tendrán facilidades para el comercio exterior, así como la desgravación de las contribuciones de manera decreciente en el tiempo.

En contraste con lo anterior, algunos analistas coinciden que la idea de las ZEE en sus intenciones es buena, pero de alcances limitados y con varios riesgos, por ejemplo, que se conviertan en grandes elefantes blancos (Barba, 2014). Según Bravo (2016) "son una decisión que apunta en dirección contraria a las demandas de los crecientes movimientos sociales en contra de la implementación de megaproyectos y de defensa del territorio que proliferan en el país"; por su parte, Ruiz (2016) señala “que no hay duda que el desarrollo de las ZEE está en riesgo: ¿Qué inversio- 
nista va a poner su dinero en zonas con elevada ingobernabilidad frente a otras alternativas en el país o en el extranjero?”. Cruz Malpica (2016) señaló la existencia de un catálogo de riesgos que se tienen que afrontar con la instalación de las ZEE, entre los que destacan: "la tenencia de la tierra, la seguridad, los derechos originarios de los pueblos, la sustentabilidad, el equilibrio ecológico, el fracking, el perfil de los inversionistas que vienen.

El presente documento se divide en tres apartados: en el primero se describen los conceptos, la clasificación y las identificación de ZEE en mundo; en el segundo, se realiza un seguimiento y análisis del proyecto de implementación de ZEE en México, en el que se identifican tres rasgos principales: el papel activo que deberá jugar el sector público-privado para cumplir con la normatividad y las instancias emanadas de la Ley de ZEE; los beneficios económicos y fiscales para las entidades federativas y las empresas donde se ubicaran las ZEE; así como la falta de condiciones de consulta e infraestructura para que operen las ZEE; en el tercer y último punto se discutirá en torno las condiciones que guardan las ZEE cuando han alcanzado un estatus de éxito o fracaso, tomando en consideración variables como crecimiento y desarrollo, empleo, flujos de capital, burocracia y conflictos de interés entre el sector inmobiliario y las áreas rurales.

\section{Aspectos metodológicos considerados.}

La presente investigación se realizará con base en un análisis descriptivo de las acciones que realiza el sector público-privado para promover los beneficios económicos y fiscales en las cuatro ZEE descritas. En ese tenor, se revisan algunos de los objetivos que considera la Ley de Zonas Económicas Especiales (LZEE), así como las instituciones que han sido creadas para su operatividad y el papel de la iniciativa privada.

De igual forma, se efectúa una investigación sobre la evolución de la pobreza y pobreza extrema, de acuerdo con datos del Consejo Nacional para la Evaluación (CONEVAL); y el grado de marginación de los estados donde se encuentran ubicadas las ZEE designadas por el gobierno federal, seleccionándose un periodo de tiempo de cinco años para el caso de la pobreza y 25 años para reflexionar sobre la marginación en Michoacán, Oaxaca, Chiapas y Veracruz. En este apartado, se elaboran cuadros estadísticos en los que se incluyen datos relativos y absolutos, además de la identificación de rankings sobre el índice de marginación, de acuerdo con información obtenida del Consejo Nacional de Población (CONAPO).

A la par del análisis planteado, se utiliza como fuente de referencia, la experiencia adquirida por el $\mathrm{BM}$ en el tema asociado al funcionamiento de las ZEE en el mundo. La información generada por dicha instancia permitirá definir si las cuatro ZEE que son objeto de estudio podrán alcanzar el éxito o fracaso, en función de los hallazgos encontrados en la operación de otras ZEE 
en el concierto internacional, especialmente de Asia, Latinoamérica y África.

\section{Origen, definición, clasificación y beneficios de las ZEE.}

Las primeras ZEE modernas registran su origen en Irlanda en 1958 [La Zona Libre del Aeropuerto de Shannon] (BM, 2008: 3), lo que se asocia al concepto de Espacio Económico (EE) establecido por Francoise Perroux (1964); por su parte al Continente Asiático llegaron a partir de la década de 1970, destacando los casos de China, India, Filipinas, Corea del Sur e Indonesia.

Las ZEE registran conceptos diversos, de acuerdo con el Reporte del Foreing Investment Advisory Service (FIAS, por sus siglas en inglés) del BM, las ZEE son áreas geográficas demarcadas contenidas dentro de los límites nacionales de un país donde las reglas de los negocios son diferentes de aquellas que prevalecen en el territorio nacional, en las que se acuerda principalmente con condiciones de inversión, comercio internacional, aduanas e impuestos, donde la zona este dada por un ambiente de negocios más liberal y efectivo que lo que se da en el territorio nacional (BM, 2008: 27)

Las ZEE está formalmente definida como un área pequeña demarcada dentro del territorio de un país aislada apropiadamente para adoptar políticas adaptables y flexibles en actividades económicas externas para atraer y alentar la inversión extranjera, o bien como áreas económicas especiales abiertas externamente o aisladas domésticamente donde la economía de mercado se convierte en la ley dominante del valor (Jao y Leung, 1986:10)

Para la Presidencia de la República del Gobierno de México (2017) “una ZEE es un área delimitada geográficamente, ubicada en un sitio con ventajas naturales y logísticas para convertirse en una región altamente productiva. Las ZEE ofrecen un entorno de negocios excepcional para atraer las inversiones y generar empleos de calidad, considerando entre otros elementos: beneficios fiscales y laborales, régimen aduanero especial, marco regulatorio ágil, infraestructura de primer nivel, programas de apoyo (capital humano, financiamiento, innovación), otros insumos y condiciones preferenciales.

En síntesis, las ZEE son áreas geográficas aisladas en un territorio o EE, que están sujetan a la aplicación de privilegios, preferencias o incentivos económicos para empresas que buscan invertir sus capitales en sectores económicos estratégicos, contando en todo momento con una normatividad o legislación flexible para su funcionamiento.

De acuerdo con la clasificación del BM (2008) y de los autores Pakdeenurit Suthikarnnarunai y Rattanawong (2014) existen seis tipos de ZEE:

- Zonas de Libre Comercio (ZLC): son áreas pequeñas delimitadas físicamente, situadas 
en puertos de entrada para almacenamiento y depósito de mercancías para su reexportación (ejemplo: zonas francas españolas o la libre de Colón en Panamá).

- Zonas de Procesamiento de Exportación (ZPE): son zonas francas industriales orientadas a la exportación, están destinadas a la fabricación para una posterior exportación.

- Puertos libres o francos: ocupan áreas territoriales extensas, tienen capacidad para todo tipo de actividades (servicios turísticos y ventas al por menor), permitiendo la residencia de personas en su interior, así como un mayor número de incentivos y beneficios. Los puertos francos a gran escala en China son un ejemplo tradicional.

- Zonas de empresas: revitalizan las zonas urbanas o rurales en dificultades, mediante incentivos fiscales y subvenciones financieras. La mayoría de las zonas se encuentran en países desarrollados, por ejemplo, Estados Unidos, Francia y Reino Unido.

- Fábricas individuales orientadas a la exportación: las fábricas no tienen que ubicarse dentro de una zona designada para recibir incentivos y privilegios. Los principales ejemplos son las ZPE ubicada en Islas Mauricio, Madagascar, México y Fiji.

- Zonas especializadas: contienen un propósito especial o específico. Los ejemplos más conocidos son los parques científicos y tecnológicos, zonas petroquímicas, de logística y almacenamiento, de juego y financieras.

De acuerdo con la clasificación presentada, las ZEE que son objeto de estudio de la presente investigación están ubicadas como ZLC y ZPE, ya que se podrán almacenar mercancías en los puertos de Lázaro Cárdenas, Salina Cruz, Puerto Chiapas y Coatzacoalcos, para su reexportación posterior. De igual forma, dichas ZEE serás susceptibles a la generación de producción industrial orientada a la exportación vía puertos.

Farole (2011) identifica cuatro categorías de variables independientes que contribuyen a explicar el funcionamiento de una ZEE: factores tradicionales (incentivos fiscales, salarios bajos y tratamiento comercial preferencial); el clima de inversión local (infraestructura, entorno administrativo a nivel local para las empresas que operaran en la zona); clima de inversión nacional (infraestructura, trámites administrativos y el entorno político a nivel nacional que también afectará el coste de producción); y el acceso a mercados (la situación geográfica de la ZEE y su facilidad para acceder al mercado regional nacional y global).

La dinámica macroecónomica mundial también puede afectar los resultados de las ZEE. Dentro de una ZEE, la situación, la comunicación con las redes de transportes y la facilidad para realizar transacciones, así como la calidad de la infraestructura, son los factores que parecen tener un impacto más fuerte en su rendimiento; mientras que salarios bajos, incentivos fiscales y tratos comerciales preferenciales consideran no tener un efecto tan crucial en su rendimiento (Farole, tomado en Arteaga et al, 2016: 34-35). 
Taverner (2007) señalaba que las ZEE tienen como características básicas: el otorgamiento de incentivos fiscales, mayor independencia en actividades de comercio internacional y en el establecimiento de cuatro principios: la construcción se enfoca en atraer y usar capital extranjero, las formas de construcción empresarial son fundamentalmente en Joint Ventures, la producción se destina fundamentalmente a la exportación y la actividad económica se rige por las leyes del mercado. Para la AFDZEE (2016), lo factores que distinguirán las ZEE en México con otras del mundo será contar con un enfoque integral, que considere los siguientes instrumentos de planeación:

- Un programa de desarrollo que tome en cuenta el ordenamiento territorial, infraestructura, políticas públicas y acciones en el Área de Influencia.

- Un plan maestro, con características para la construcción, desarrollo, administración y mantenimiento.

- $\quad$ Ubicación estratégica con alto potencial productivo y logístico, proyectos de infraestructura (conectividad).

- $\quad$ Agresivo paquete de incentivos fiscales, ventanilla única para simplificar y agilizar los trámites y regulaciones de empresas.

- Identificación del potencial productivo actual y latente de las regiones que albergarán las ZEE; así como la identificación de vocaciones productivas para las ZEE.

Para Sigler (2014) "en los últimos 40 años, las ZEE han surgido como una amplia estrategia para atraer IED, desarrollo y crecimiento económico (Wong and Chu, 1984; Brautigam and Xiaoyang, 2011). La racionalidad para delinear la creación de una ZEE es atraer IED, a través de incentivos económicos para países que no tienen disponibilidad de desarrollar sus industrias domésticas o por la necesidad de estímulos económicos en regiones subnacionales específicas (Chen, 1994; Ge, 1999).

Algunos críticos de las ZEE han argumentado que incluso donde se implementaron, ellas son inferiores para complementar la liberalización económica (Farole, 2011). Otros han acentuado en la necesidad para que sectores sean desarrollados en complementariedad a otros, criticando la capacidad limitada para aprender o generar tecnología, o incluso encuentran que las ZEE actualmente exacerban la disparidad del ingreso entre regiones (Sigler 2014, tomando a Park, 2005)

La forma y función de las ZEE ha cambiado considerablemente desde su incepción original. Las ZEE contemporáneas son generalmente más específicas en función de las que ellas fueron y han evolucionado en el tiempo para incorporar componentes de alto valor añadido. En particular, parques científico y zonas de crecimiento transfronterizo han surgido en respuesta de empujar grandes efectos tecnológicos y trabajo innovativo (Chen, 1995) con un enfoque más centrado en las industrias creativas (Florida, 2002). 


\section{$\rightarrow$ 4. Identificación de ZEE en el contexto internacional.}

Para el BM (2008), el crecimiento de las ZEE ha sido destacado a partir de la década de 1990. Una de las características más importantes ha sido la generación de más de 68 millones de empleos directos y más de 500 mil millones de dólares en valor agregado relacionado con el comercio en las más de 3,000 ZEE ubicadas en 135 países en todo el mundo hasta 2007, de las cuales $90 \%$ se encontraba en Asia. Cabe destacar, que 62\% de las 2,301 zonas de países en desarrollo eran operadas por el sector privado a principios de la década de los noventa, contrario a lo que ocurría en 1980, cuando dicho porcentaje representaba menos del 25\%. Al respecto, surge la siguiente pregunta ¿Cómo le ha hecho el sector privado para incrementar su participación en la operación de las ZEE en el contexto internacional?. El factor clave han sido las facilidades otorgadas a los desarrolladores, quienes son capaces de reducir los costos de ubicación que una ZEE genera para el gobierno (BM, 2008: 2).

Para los países en desarrollo, las ZEE tienen dos racionalidades: en política pueden ser una herramienta útil para generar una estrategia de crecimiento integral en materia de competitividad industrial y de atracción de IED; en términos de eficiencia de gobierno, estos se ayudan a desarrollar y diversificar exportaciones, mientras mantienen barreras proteccionistas para crear empleos y pilotear nuevas políticas y enfoques en el ámbito de aduanas, legal, laboral y de propiedad público privada (BM, 2008:1)

En ese contexto, en este documento se describen algunos ejemplos de ZEE que funcionan con una mayor visibilidad en el concierto internacional ${ }^{1}$, resaltando las siguientes regiones:

\section{i. Asia.}

De acuerdo con González (2003) y Leung (1984; IV), en 1979², el gobierno chino decidió establecer cuatro ZEE en las provincias de Guangdong (Shuhau, Shenzhen y Shantou) y Fujian (Xiamen) en la zona costera, autorizándose a las administraciones locales tomar medidas para mejor su medio ambiente económico, infraestructura, servicio y para establecer oficinas de consultoría y servicios a instituciones. En 1983 se crearon nuevas zonas de inversión prioritaria y en 1984 se establecieron 14 ciudades portuarias o costeras, que eran identificadas como zona de desarrollo técnico-económico (ZDTE); entre 1988 se convirtió a la Isla de Hainan como quinta ZEE; en 1990 se impulsó al Distrito de Pudong, Shanghai, en 1992 se ratificó la creación de 32 ZDTE (González, 2003: 190-191). Actualmente en China existen más de 300 ZEE, reconociendo una división de sie-

1 Según el BM (2008) hay un pequeño número de países que cuentan con la mayoría de ZEE en el mundo.

2 Para Graham (2004). La creación de ZEE en China se originó con el proceso de apertura a la inversión en los setenta, con el apoyo de la Ley de Inversión de Empresas Conjuntas en 1978, cuyo principal objetivo era atraer tecnología para el sector industrial propiedad del estado y para mejorar la calidad de los servicios. 
te tipos: ZDTE, de desarrollo de alta tecnología industrial, ZLC, económicas fronterizas, ZPE, de desarrollo provincial (Cowaloosur, 2013: 95).

Según González (2003) y Chu and Wong (1985) China implementó medidas preferenciales para los inversionistas extranjeros que se asentaron en las ZEE y las ZDTE, con el objeto de

- $\quad$ Exención de impuestos durante los primeros dos años a empresas manufactureras con programas de inversión foránea instaladas en un periodo no menor a 10 años; y del 50\% de reducción desde el tercero al quinto año.

- $\quad$ Tasa preferencial del $15 \%$ a empresas manufacturas que se instalarán su IED en la costa.

- $\quad$ Exención de aranceles y del Impuesto al Valor Agregado (IVA) a bienes manufacturados vendidos en el extranjero

- $\quad$ Exención de aranceles e IVA para insumos importados que se usarán para la producción.

- $\quad$ Exención de aranceles de exportación a los bienes producidos por empresas extranjeras.

- $\quad$ Libertad de repatriar y remitir ganancias

- $\quad$ Bajos costos de la mano de obra y la provisión de infraestructura estándar de las empresas.

- $\quad$ Vivienda, amenidades y servicios de apoyo

- Administración simplificada para unificar los procedimientos administrativos en la zona.

En la India, las ZEE fueron introducidas como una iniciativa económica espacial en 2000 y estructurada dentro de la legislación relevante en 2005, hay actualmente alrededor de 700 ZEE operacionales en dicho país, de acuerdo con el Ministerio de Comercio e Industria de la India (2006) (Cowaloosur, 2013: 95). Las ZEE de la India pueden ser desarrolladas por el gobierno central o estatal, sector privado o por ambos, bajo un esquema de joint venture.

Por su parte, en recientes décadas, el gobierno de Filipinas implementó una serie de políticas neoliberales para estimular la competitividad económica global del país. Una de ella fue el establecimiento de ZEE (Acta de ZEE 1995) (A.A Ortega et al, 2015, Makabenta 2002), la cual ayudó a transformar áreas selectas en el país dentro de zonas económicas de clases mundial altamente desarrolladas para atraer IED, con el objeto de crear empleo y consumo de materias primas. Dichas políticas han impactado la dirección y la magnitud de la urbanización en Filipinas (tomado de Kelly 2000 Y Ortega 2012).

La Philippine Economic Zone Authority (PEZA, por sus siglas en inglés) se ha convertido 
en nodo crítico del capital global y crecimiento demográfico, donde se promueve proyectos residenciales y comerciales para proveer la demanda de vivienda. Todo esto resulta en un incremento de actividades económicas y de urbanización. En 2007, la National Economy Development Authority (NEDA, por sus siglas en inglés) reconoció y delimitó 12 configuraciones metropolitanas urbanas (A.A. Ortega, et al, 2015: 131): Manila, Bicol, Lloilo-Bacolod, Cebu, Leyte-Samar, CDO-Noroeste de Mindanao, Davao, Lanao, Cotabato, Santos Generak, Zamboanga.

ii. África.

Cowaloosur (2013) refiere a las ZEE en África (CSEZAs ${ }^{3}$, por sus siglas en inglés). La aplicación del modelo y su advenimiento alteró la exclusividad de apropiación de tierra africana, a través de agro proyectos de inversión individuales. CSEZAs ha sido traspuesta a cinco países africanos: Nigeria, Etiopia, Egipto, Zambia y Mauricio (Cowaloosur, 2013: 94). Las ZEE son implementadas, a través de compañías chinas, quienes pasan por trámites exhaustivos requeridos por el Ministerio de Comercio de dicha economía (MOFCOM), sin considerar si son empresas privadas o propiedad del estado.

El gobierno chino retiene el activismo, mediante el apoyo fiscal que proporciona: concesiones, prestamos de largo plazo, subsidios sobre los costos de estudios de factibilidad, de viajes, mercado, renta de tierra inicial, a través del fondo de cooperación económica y de comercio del MOFCOM: concesiones o becas: reembolsos de la mitad de gastos de movilidad; devolución de impuestos a la exportación y la importación de venta de materiales de la construcción, facilidad para acceder al intercambio de moneda extranjera, elegibilidad para acceder a fondos especiales para la cooperación económico y tecnológica (Cowaloosur, 2013: 97-98).

Se observa que sin considerar si las compañías desarrolladoras de CSEZAs son privadas o públicas, el gobierno chino retiene el dominio de las CSEZAs, a través de su autoridad para seleccionar al desarrollador, proporcionando los fondos y también porque las CSEZA son esencialmente empresas del estado bilaterales entre China y los países de África, por ello es imperativo que el gobierno chino monitorea cercanamente el despliegue de dichas zonas; China contribuye hacia las CSEZA en forma de capital y África con su tierra y recursos.

\section{iii. Latinoamérica.}

Panamá adoptó las ZEE como estrategia pilar de su desarrollo, destacando la Zona Libre de Colón y la Panamá Pacifico. Según Sigler (2010) las dos ZEE prometían desarrollar 70 mil empleos ( $5 \%$ del total de base de empleo del país). No obstante a lo anterior, se registrará una estructura de

3 La implementación del modelo de ZEE de China en África forma parte del discurso del Presidente Hu Jintao en el Foro de Cooperación China-África repletó de alusiones sobre mutualidad y cooperación. Uno de los compromisos de China con el continente fue establecer de 3 a 5 zonas de cooperación económica en los siguientes tres años. 
impuestos regresiva, en forma de exoneraciones de impuestos, reducción de tarifas y de impuestos por ingresos, asegurando beneficios fiscales mínimos. En términos de beneficio directo al Estado contará con un ingreso-neutral cercano a los US\$4.9 millones de dólares y 1.6 millones de dólares en ganancias netas en los primeros tres cuartos de 2010 (Contraloría General de la República de Panamá, 2010).

Para el 2014 el estado planeaba atar un desembolso por 4.6 millones entre las dos ZEE. La Zona libre de Colón es la segunda ZLC más grande del mundo y se especializa en la reexportación de bienes de consumo en América. La Pacífico Panamá es una mezcla de megaproyectos integrando un parque de negocio internacional con una comunidad con estilo de vida cosmopolita. Ambos se han posicionado para apuntalar la economía de Panamá para desarrollar una fuerte ventaja competitiva en el sector terciario.

En México se ubica la instalación de ZEE, a través de la Programa Mexicano de Maquiladoras, el cual considera alrededor de 3,700 fábricas expandidas en todo el país, con una generación de aproximadamente millón de empleos, además de exportaciones cercanas a los 80 mil millones de dólares por año. De igual forma, se identifican actividades industriales altamente diversificadas con fuerte IED de Japón y Estados Unidos de América (BM, 2008:26).

\section{iv. Europa.}

La zona Libre de Shannon, Irlanda es la primera ZEE del mundo (1958) inspirada en el desarrollo de ZPE en mercados emergentes, a través de la búsqueda del crecimiento económico y de las exportaciones, así como de la IED orientada a la economía del país; por su parte en Francia existe el Programa de 85 zonas urbanas libres modelado, a través de las zonas empresariales del Reino Unido y de las de empoderamiento de Estados Unidos.

\section{5royecto de ZEE en México: seguimiento y análisis de su implementación.}

De acuerdo con la LZEE (2016), lo que se busca lograr en la región sureste es un crecimiento económico sostenible, reducir la pobreza, proveer de servicios básicos y expandir de oportunidades para vidas saludables y productivas, en las zonas del país que tengan mayores rezagos en desarrollo social, a través del fomento de la inversión, la productividad, la competitividad, el empleo y una mejor distribución del ingreso entre la población.

En este apartado se revisaran, como prediagnóstico algunos aspectos demográficos, económicos y sociales de las entidades federativas donde se ubican las ZEE; las acciones de gobierno para operar las ZEE; la descripción de beneficios económicos y fiscales que otorgará el estado a las empresas; así como la vertiente del riego a las inoperatividad. 


\subsection{Población, economía, pobreza y marginación en ZEE.}

5.1.1. Datos de población urbana, rural e indígena en ZEE.

La población de las cuatro entidades que conforman las ZEE era de 21.7 millones de habitantes en 2015 , lo que representaba $18.1 \%$ nacional, localizado en una extensión territorial de 301,930 kilómetros cuadrados (15.3\% del total nacional). Destacan la situación de Michoacán y Veracruz donde su población es predominantemente rural, 68 y 61\%, respectivamente; en los cuatro estados se concentra casi $40 \%$ de la población indígena del país, resaltando la situación de Oaxaca y Chiapas, donde el 43.7 y $32.7 \%$, respectivamente de las poblaciones de dichas entidades eran indígenas en 2015 (Tabla 1).

Tabla 1

Datos demográficos de las entidades que conforman las ZEE en México, 2014

\begin{tabular}{|r|c|c|c|c|c|c|c|}
\hline Entidad & Población* & $\begin{array}{c}\text { Extensión } \\
\text { territorial } \\
\text { Km2* }\end{array}$ & $\begin{array}{c}\text { Densidad } \\
\text { de } \\
\text { población } \\
\text { Km2 }\end{array}$ & $\begin{array}{c}\text { \% } \\
\text { Población } \\
\text { urbana** }\end{array}$ & $\begin{array}{c}\text { \% } \\
\text { Población } \\
\text { rural** }\end{array}$ & $\begin{array}{c}\text { Población } \\
\text { indígena*** }\end{array}$ & $\begin{array}{c}\text { Porcentaje } \\
\text { de } \\
\text { población } \\
\text { indígena }\end{array}$ \\
\hline Chiapas & $5,197,565$ & 73,887 & 70.3 & 51 & 49 & $1,706,017$ & 32.7 \\
\hline Michoacán & $4,571,753$ & 59,864 & 76.4 & 31 & 68 & 237,655 & 5.2 \\
\hline Oaxaca & $3,989,130$ & 95,364 & 41.8 & 53 & 47 & $1,734,658$ & 43.7 \\
\hline Veracruz & $7,989,354$ & 72,815 & 109.7 & 39 & 61 & $1,101,306$ & 13.6 \\
\hline
\end{tabular}

Fuente. Elaboración propia con base en datos de INEGI*, CEFP** 2014-2015, Comisión Nacional para el Desarrollo de los Pueblos Indigenas***.

5.1.2. PIB, IED, empleo e ingreso en ZEE.

Con relación a la situación económica de las entidades federativas donde se ubican las cuatro ZEE (Michoacán, Oaxaca, Chiapas y Veracruz), estas generaron menos del 11\% del total del $\mathrm{PIB}^{4}$ en 2015, registrando en todos los casos crecimientos menores al promedio del PIB nacional entre 2014 y 2015, cuya variación fue del 2.53. Oaxaca destacó con la mejor tasa de crecimiento al presentar un aumento de 1.53, mientras que Chiapas expuso una tasa negativa de -3.31 (Tabla 2). En términos absolutos de PIB, Chiapas fue el menos productivo con 227,598 millones de pesos y Veracruz tuvo el mayor producto con 675,532 millones de pesos (Tabla 2). La región generó 1.3 billones de pesos (10.7\% del total nacional), cifra cercana a lo que se capta por el concepto de Impuesto sobre la Renta (ISR) a nivel federal.

4 Según INEGI (2015) Las entidades que sobrepasaron el billón de pesos de producción fueron: Ciudad de México (2, 312,562 pesos); Estado de México (1, 230,628 pesos); Nuevo León (1, 041,797 pesos); mientras que las entidades con menos producción fueron en 2015 fueron Tlaxcala con 75,578 y Colima con 81,672 pesos. 
Tabla 2

PIB a precios constantes de 2008 de los estados que conforman las ZEE, 2014-2015

\begin{tabular}{|l|r|r|r|r|r|}
\hline \multirow{2}{*}{ Entidad } & \multicolumn{2}{|l|}{$\begin{array}{l}\text { PIB en millones de pesos a } \\
\text { precios constantes de 2008 }\end{array}$} & \multicolumn{2}{l|}{$\begin{array}{l}\text { Variación porcentual del PIB } \\
\text { en valores constantes }\end{array}$} & $\begin{array}{l}\text { \% del PIB } \\
\text { nacional } \\
\end{array}$ \\
\cline { 2 - 6 } & 2014 & 2015 & 2014 & 2015 & \multicolumn{2}{c|}{ (2015) } \\
\hline Chiapas & 235,387 & 227,598 & 2.59 & -3.31 & $1.72(20)$ \\
\hline Michoacán & 317,819 & 318,401 & 5.97 & 0.18 & $2.40(14)$ \\
\hline Oaxaca & 210,571 & 213,783 & 2.80 & 1.53 & $1.60(22)$ \\
\hline Veracruz & 675,352 & 676,899 & 0.07 & 0.23 & $4.99(5)$ \\
\hline Nacional & $13,403,815$ & $13,743,338$ & 2.17 & 2.53 & $100 \%$ \\
\hline
\end{tabular}

Fuente: Elaboración propia con base en cifras revisadas en INEGI, 2015.

De acuerdo con información del Centro de Estudios de las Finanzas Públicas (CEFP) tomada de INEGI (2014-2016), en términos de IED, las cuatro entidades captaron 2,100 millones de dólares, de los 30,284.6 que ingresaron al país en 2015, es decir $8 \%$ del total nacional, lo que resulta poco significativo para las necesidades de la región y de la nación. Veracruz obtuvo $40 \%$ de la IED de la región de las ZEE, además de exportar 1.8\% nacional (Tabla 3).

Tabla 3

Comportamiento de algunas variables económicas en entidades de las ZEE, 2016-2016

\begin{tabular}{|l|r|r|r|r|r|r|}
\hline Entidad & \multicolumn{1}{|c|}{$\begin{array}{c}\text { IED (2015) } \\
\text { Mdd }\end{array}$} & $\begin{array}{l}\text { Exportaciones } \\
\text { (2014) en mdd }\end{array}$ & $\begin{array}{c}\text { Pib per } \\
\text { cápita mdp } \\
\text { (2014) }\end{array}$ & $\begin{array}{l}\text { C.G } \\
\mathbf{2 0 1 4}\end{array}$ & $\begin{array}{l}\text { Tasa de } \\
\text { desocupación } \\
\text { (2016) }\end{array}$ & $\begin{array}{l}\text { Ingreso } \\
\text { corriente } \\
\text { (2014)** }\end{array}$ \\
\hline Chiapas & 138.0 & $1,464,088(0.4)$ & 45,631 & 0.4628 & 3.1 & 22,603 \\
\hline Michoacán & 302.6 & $1,099,319(0.3)$ & 69,967 & 0.4333 & 2.7 & 29,846 \\
\hline Oaxaca & 231.4 & $1,359,228(0.3)$ & 52,598 & 0.4791 & 2.1 & 24,041 \\
\hline Veracruz & $1,536.9$ & $7,292,955(1.8)$ & 85,062 & 0.4461 & 3.7 & 28,029 \\
\hline Nacional & $30,284.6$ & $397,128,659$ & 112,634 & 0.4644 & 4.9 & 40,000 \\
\hline
\end{tabular}

Fuente: elaboración propia para todos los datos basados en información del CEFP, con información del Módulo de condiciones socioeconómicas, 2014. INEGI.

** Distribución trimestral del ingreso corriente por entidad federativa 2014.

Para Coeficiente de GINI: http://catalogo.datos.gob.mx/dataset/valor-del-coeficiente-de-desigualdad-gini-nacional-y-por-entidad-federativa-2010-2012.

Las bajas cifras de PIB, IED y de generación de exportaciones se reflejan en un PIB per cápita inferior al promedio nacional, que en 2014 fue de 112,634 pesos (Tabla 3). Resalta el caso de Veracruz con el mayor per cápita de las cuatro ZEE con 85,062 pesos, mientras que Chiapas mostró el comportamiento más bajo con 45,631. Con relación al ingreso corriente nacional en 2014 fue de 40 mil pesos, el diferencial entre Chipas y Veracruz osciló entre los 22,603 y los 28,029 pesos (el más alto y el más bajo). Estamos hablando de ingresos corrientes por persona menor a los 1,500 pesos por mes y 500 pesos por semana, insuficientes para resolver los satisfactores básicos. Como referente, la Ciudad de México tuvo un ingreso corriente en 2016 de 58,351 pesos. A la par del 
PIB y el ingreso corriente, se identifica que el Coeficiente de Gini se ubicaba por encima del .40 en todos los casos, incluyendo el contexto nacional, lo que se refleja en una fuerte desigualdad del ingreso para la región.

5.1.3. Pobreza, pobreza extrema, marginación migración ZEE.

La variación de población en pobreza de las cuatro entidades federativas donde se ubican las ZEE de 2010 a 2014 continua siendo constante, pero alta en porcentaje. De acuerdo con datos de CONEVAL (2014), Chiapas registró un 76.2\% del total de población en condiciones de pobreza, Oaxaca $66.8 \%$, Michoacán con $66.8 \%$ y Veracruz con $58.0 \%$. Entre los cuatro estados suman más de 14 millones de personas de los 55.3 millones en dicha condición a nivel nacional (Tabla 4).

Tabla 4

Evolución de la pobreza en entidades federativas ubicadas en la ZEE, 2012-2014

\begin{tabular}{|l|c|c|c|r|r|r|}
\hline \multirow{2}{*}{ Entidad federativa } & \multicolumn{3}{|c|}{ \% de Pobreza } & \multicolumn{3}{c|}{ Miles de personas } \\
\cline { 2 - 7 } & $\mathbf{2 0 1 0}$ & $\mathbf{2 0 1 2}$ & $\mathbf{2 0 1 4}$ & $\mathbf{2 0 1 0}$ & $\mathbf{2 0 1 2}$ & \multicolumn{2}{c|}{$\mathbf{2 0 1 4}$} \\
\hline Chiapas & 78.5 & 74.7 & 76.2 & $3,866.3$ & $3,782.3$ & $3,961.0$ \\
\hline Michoacán & 54.7 & 54.4 & 59.2 & $2,424.8$ & $2,447.7$ & $2,708.6$ \\
\hline Oaxaca & 67.0 & 61.9 & 66.8 & $2,596.3$ & $2,424.6$ & $2,662.7$ \\
\hline Veracruz & 57.6 & 52.6 & 58.0 & $4,448.0$ & $4,141.8$ & $4,634.2$ \\
\hline Nacional & 46.1 & 45.5 & 46.2 & $52,813.0$ & $53,349.9$ & $55,341.6$ \\
\hline
\end{tabular}

Fuente: Elaboración propia con base en datos de CONEVAL:

http://www.coneval.org.mx/Medicion/MP/Paginas/Pobreza_2014.aspx.

Con respecto a la pobreza extrema, de los 11.53 millones de mexicanos en dicha situación en 2014, la región de estudio concentró más 5 millones, lo que representó alrededor del 50\% nacional. Chiapas registró $31.8 \%$ del total de su población en pobreza extrema, Oaxaca el 28.3\%, Michoacán 14.0 y Veracruz 17.2\% (Tabla 5).

Tabla 5

Evolución de la pobreza extrema en entidades federativas ubicadas en la ZEE: 2012-2014

\begin{tabular}{|l|r|r|r|r|r|r|}
\hline \multirow{2}{*}{ Entidad federativa } & \multicolumn{3}{|c|}{ \% de Pobreza } & \multicolumn{3}{c|}{ Miles de personas } \\
\cline { 2 - 7 } & $\mathbf{2 0 1 0}$ & $\mathbf{2 0 1 2}$ & $\mathbf{2 0 1 4}$ & $\mathbf{2 0 1 0}$ & $\mathbf{2 0 1 2}$ & $\mathbf{2 0 1 4}$ \\
\hline Chiapas & 38.3 & 32.2 & 31.8 & $1,885.4$ & $1,629.2$ & 64.4 \\
\hline Michoacán & 13.5 & 14.4 & 14.0 & 598.0 & 650.3 & $1,130.3$ \\
\hline Oaxaca & 29.2 & 23.3 & 28.3 & $1,133.5$ & 916.6 & $1,370.5$ \\
\hline Veracruz & 18.8 & 14.3 & 17.2 & $1,449.0$ & $1,122.0$ & $11,442.3$ \\
\hline Nacional & 11.3 & 9.8 & 9.5 & $12,964.7$ & $11,529.0$ & \\
\hline
\end{tabular}

Fuente: Elaboración propia con base en datos de CONEVAL:

http://www.coneval.org.mx/Medicion/MP/Paginas/Pobreza_2014.aspx 
La pobreza se visualiza o apropia directamente con el grado de marginación: según datos de CONAPO, de 1990 a 2015, Chiapas se mantuvo entre el primer y segundo con el mayor grado de marginación en México; Oaxaca entre el segundo y tercer lugar; Veracruz entre cuarto y quinto Michoacán entre el 12 y el 10. En 25 cinco años de medición de dicho indicador, se observa un progreso mínimo del área de estudio, permaneciendo como la zona de mayor marginación del país sin incluir al Estado de Guerrero, que ocupa el primer lugar desde 2005 hasta la actualidad (Tabla 6).;

Tabla 6

Índice de marginación en entidades federativas ubicadas en ZEE, 1990-2015

\begin{tabular}{|l|c|c|c|r|r|r|}
\hline \multirow{2}{*}{ Entidad federativa } & \multicolumn{3}{|c|}{ \% de Pobreza } & \multicolumn{3}{c|}{ Miles de personas } \\
\cline { 2 - 7 } & $\mathbf{2 0 1 0}$ & $\mathbf{2 0 1 2}$ & $\mathbf{2 0 1 4}$ & $\mathbf{2 0 1 0}$ & $\mathbf{2 0 1 2}$ & $\mathbf{2 0 1 4}$ \\
\hline Chiapas & 78.5 & 74.7 & 76.2 & $3,866.3$ & $3,782.3$ & $3,961.0$ \\
\hline Michoacán & 54.7 & 54.4 & 59.2 & $2,424.8$ & $2,447.7$ & $2,708.6$ \\
\hline Oaxaca & 67.0 & 61.9 & 66.8 & $2,596.3$ & $2,424.6$ & $2,662.7$ \\
\hline Veracruz & 57.6 & 52.6 & 58.0 & $4,448.0$ & $4,141.8$ & $4,634.2$ \\
\hline Nacional & 46.1 & 45.5 & 46.2 & $52,813.0$ & $53,349.9$ & $55,341.6$ \\
\hline
\end{tabular}

* Nota: los números entre paréntesis representan la posición de marginación alcanzada en México.

Fuente: Elaboración propia con datos CONAPO 1990-2015.

La pobreza, alta marginación y bajo desarrollo humano obligan a la población a emigrar y buscar nuevas oportunidades de empleo y bienestar para sus familias. De acuerdo con el Anuario de Migración y Remesas que elaboraron la Fundación BBA Bancomer y CONAPO (2014: 86 y 133-134), Michoacán mantiene la segunda posición nacional con el mayor número de emigrantes mexicanos (según estado de nacimiento) entre 2010 y 2014 con un total de 65,298 personas; Veracruz está en sexto lugar con 30,030 personas; Tres de las cuatro entidades se encuentran entre las 10 con mayor emigración del país.

En 2014, Michoacán fue la entidad con el mayor número de repatriados del país con 23,138 mexicanos, seguido por Oaxaca con 20,785; en octavo lugar esta Veracruz con 12,223; y en el 11 Chiapas con 10,488 .

Con respecto al indicador de migrantes mexicanos por retorno de residencia al regreso (2009-2014). Solo Michoacán destaca en este indicador con el 8.4\% (tercer lugar). El resto de los estados no registra una participación representativa, lo que significa que dichas entidades no están absorbiendo la mano de obra de retorno. Guanajuato y el D.F. registran el primer y segundo lugar en este rubro con el 8.8. y 8.7\%, respectivamente.

Con relación a las remesas por estado, de los 24,948 millones de dólares recibidos en el

5 La medición de pobreza utiliza dos líneas de ingreso: la línea de bienestar mínimo, que equivale al valor de la canasta alimentaria por persona al mes; y la línea de bienestar, que equivale al valor total de la canasta alimentaria y de la canasta no alimentaria por persona al mes. Bienestar mínimo (canasta alimentaria): valores mensuales por persona a precios corrientes. Rural (914.89 pesos) en diciembre de 2014; Urbano (1,291.93 pesos). Bienestar (alimentación más no alimentaria): Rural (1,687.02 pesos) en diciembre de 2014; Urbano (2,626.85 pesos) 
país en 2015, Michoacán atrajo el 10.1\% (primer lugar), Oaxaca 5.2\% (sexto lugar); Veracruz con $4.9 \%$, Chiapas está en el 17 con 2.4\%. 1 de cada 5 dólares de remesas fue captado por la región de estudio, lo cual lo hace incrementar su independencia en este rubro. En cuanto a la dependencia de las remesas con respecto al PIB estatal en 2015, para Michoacán era de 9.9\% (primer lugar); mientras que Oaxaca registró el tercer lugar con 7.4\%. A nivel nacional, las remesas son equivalentes el $2.3 \%$ del PIB.

\subsection{Acciones del gobierno para operar las ZEE en el suroeste de México.}

Lo que se describe como acciones de gobierno es la reciente creación de un marco jurídico institucional para operar las ZEE, de una Comisión Intersecretarial y de la AFDZEE; así como las actividades operativas y de difusión que realizan instancias de los sectores público-privados, los gobiernos de los estados y las cámaras y asociaciones empresariales.

\subsubsection{Ley Federal de Zonas Económicas Especiales (LFZEE).}

Fue promulgada por el Diario Oficial de la Federación el 1 de junio de $2016^{6}$. En su Artículo 6 se establece como objetivo, impulsar, a través de la inversión productiva, el crecimiento económico sostenible, sustentable y equilibrado de las regiones del país que tengan mayores rezagos en desarrollo social, siempre y cuando reúnan todos los siguientes requisitos: estados con mayor incidencia de pobreza extrema; ubicación estratégica para el desarrollo de la actividad productiva, instalación de sectores productivos con ventajas comparativas y vocación productiva en la zona, establecerse en municipios que oscilan en una población entre 50 mil y 500 mil habitantes.

La LFZEE considera la creación de un programa de desarrollo (Artículo 12), que incluya: las acciones de ordenamiento territorial y las características de las obras de infraestructura de transporte, de comunicaciones, de logística, energética, hidráulica, ambiental y otras que se requieren ejecutar en el exterior de la Zona para la operación de la misma y, en su caso, otras que sean complemento a la infraestructura exterior, y II. Las políticas públicas y acciones complementarias que se ejecutarán para: El fortalecimiento del capital humano y El fortalecimiento de la seguridad pública en la Zona y su Área de Influencia; la innovación y desarrollo científico y tecnológico; El apoyo al financiamiento; la provisión de servicios de soporte para Inversionistas; la promoción del encadenamiento productivo de pequeñas y medianas empresas: Fomentar la creación y el fortalecimiento de incubadoras de empresas; El fomento al desarrollo económico, social y urbano del Área de Influencia; Establecimiento de mecanismos de cooperación entre la ZEE y la API; La sustentabilidad, protección y preservación del medio ambiente

6 El 1 de junio de 2017 la LZEEE cumplió un año de haber entrado en vigor 


\subsubsection{Comisión Intersecretarial de ZEE (CIZEE).}

Las dependencias, entidades y organismos que la conforman son: Secretaría de Hacienda y Crédito Público (SHCP), Secretaría de Gobernación, Secretaria de Desarrollo Social, Secretaría de Medio Ambiente y Recursos Naturales, Secretaría de Economía, Secretaría de Agricultura, Ganadería, Recursos, Pesca y Alimentación, Secretaría de Comunicaciones y Transportes, Secretaría de la Función Pública, Secretaría de Educación, Secretaría del Trabajo y Previsión Social, Secretaría de Salud y el Consejo Nacional de Ciencia y Tecnología (CONACYT) (Artículo 37 de la LZEE).

Entre las principales atribuciones de la CIZEE se destaca: el establecer la política para el establecimiento y desarrollo de zonas; aprobar el programa de desarrollo de cada zona; determinar las acciones concretas que deben ejecutar las dependencias y entidades paraestatales en congruencia con el programa de desarrollo, establecer mecanismos de coordinación para agilizar la ejecución de políticas, proyectos y acciones, así como el otorgamiento de las concesiones y demás autorizaciones por parte de las dependencias o entidades paraestatales, que sean necesarias para el establecimiento y desarrollo de zonas; solicitar, cuando lo considere pertinente, la opinión de académicos, especialistas o representantes de organismos de los sectores privado y social; (Presidencia de la República, 2017)

\subsubsection{Decreto de Creación de la Autoridad Federal para el Desarrollo de las ZEE (AFDZEE).}

De acuerdo con los artículos ( 1 al 4), la AFDZEE se constituye como un órgano administrativo desconcentrado de la SHCP o, con autonomía técnica, operativa y de gestión, la cual tiene por objeto ejercer las funciones en materia de planeación, promoción, regulación, supervisión y verificación en materia de zonas que le confiere la SHCP, así como las demás que establecen las disposiciones jurídicas aplicables.

Según el Artículo 4. Para el cumplimiento de su objeto, la AFDZEE tendrá las siguientes atribuciones en los términos de la Ley y su Reglamento: I. Implementar la política para el establecimiento y desarrollo de Zonas; II. Establecer mecanismos específicos para promover, facilitar la gestión, fomentar y financiar la planeación, establecimiento y operación de Zonas, en los términos de las disposiciones aplicables y de manera coordinada con las dependencias y entidades paraestatales de la Administración Pública Federal competentes. (Presidencia de la Repúblicas: 2016)

De acuerdo con el Diario el Economista (en su publicación del 10 de noviembre de 2016) Gerardo Gutiérrez Candiani, Jefe de la AFDZEE invitó a la Cámara Nacional de Empresas de Consultoría y a sus empresas afiliadas a sumarse a un trabajo continuo en las ZEE que, de acuerdo con él, registran un gran potencial económico. "México tiene el reto de crecer hacia dentro, tenemos oportunidades importantes para detonar como plataforma logística". En este sentido, las ZEE consideran 81 proyectos con una inversión de 87,000 millones de pesos en 10 años, de los cuales 70\% provendrá 
del sector privado". De las 10 zonas mapeadas, siete serán de nichos y tres de competencia industrial, siendo éstas: Puerto Lázaro Cárdenas, en Michoacán, puerto de Coatzacoalcos y el Istmo de Tehuantepec, que comprende del Puerto de Salinas Cruz a Puerto Chiapas. Las zonas también comprenden programa de repatriación de capital humano y servicios de educación en las áreas de influencia.

Gutiérrez Candiani (22 mayo de 2017) señaló ante el Colegio de Ingenieros de México que las ZEE son un programa disruptivo que busca generar un círculo virtuoso de riqueza en el sur-sureste a través de la inversión y el empleo. La idea es tener más y mejores empleos, con mayor inversión para fomentar las cadenas de valor, aumentar la productividad, lograr mejores niveles de ingreso y sobre todo, generar un bienestar que todavía no existe. Un gran acierto de la LZEE es que proporciona apoyos adicionales a las áreas de influencia para lograr un desarrollo sostenido y sustentable. La AFDZEE anunció que en las Zonas Económicas no habrá minería, pues se busca impulsar las manufacturas mexicanas de exportación; no habrá afectación a los pueblos indígenas, porque no se instalarán en municipios indígenas.

En el Tercer Foro de Consulta de Infraestructura organizado por la Cámara Mexicana de la Industria y la Construcción (CMIC) el 9 de mayo pasado en Oaxaca, Gutiérrez Candiani (2017) señaló que han identificado 95 proyectos de infraestructura, que en los próximos 10 años sumarían inversiones por más de 5,134 millones de dólares. En este proceso se pondrán en marcha cuatro proyectos aeroportuarios, 21 de carreteras, seis ferroviarios, 40 portuarios y un centro logístico. Además de 11 proyectos en materia de energía y 12 de agua. Se estima que 70\% de los recursos para estos proyectos provendría de fuentes privadas o mediante Asociaciones Públicas Privadas.

De acuerdo con Luna (2017) a principios de febrero de 2017, el Jefe de la AFDZEE (2017) identificó 116 empresas interesadas en invertir en las ZEE, de las cuales cerca de 25 registraban una motivación concreta. Son de varios sectores como el manufacturero, acero, alimentos, agroindustria, textil. Hay empresas extranjeras y mexicanas, de las cuales provendría una primera inversión de 7,000 millones de dólares. Por ejemplo, en Puerto Chiapas ya hay cinco empresas, en Coatzacoalcos seis, en Salina Cruz cinco, cuatro en Lázaro Cárdenas y otras cuatro en Yucatán, con las que ya hay un avance importante para cerrar las inversiones (Luna, 2017).

Por su parte, en el Boletín 02 de la AFDZEE del 27 de abril de 2017 se informaba sobre la firma de un primer Acuerdo de Colaboración con la International Enterprise Singapore (IE Singapore) con la finalidad de estrechar la relación de cooperación entre ambas instituciones, brindar apoyo mutuo para el desarrollo de las ZEE en México y aprovechar la experiencia del país que más éxito ha tenido como administrador integral en Asia. Al respecto, Sung Pei Yew de IE Singapore comentaba que con este MOU se espera fortalecer la colaboración con la AFDZEE en los sectores de infraestructura, energía y logística”. 
Como se observa, la AFDZEE demuestra un activismo permanente por difundir ante la iniciativa privada e instancias internacionales que es lo que generarán las ZEE en el ámbito de la IED y del empleo, a través de la llegada de empresas nacionales y extranjeras. Hasta el momento no se advierte un interés particular de acercarse a la sociedad en general y al sector académico en particular, con el objeto de dar a conocer también la información sobre las ZEE

\subsubsection{Conferencia Nacional de Gobernadores (CONAGO).}

En el Acuerdo No. 35 de la LI Reunión Ordinaria de la CONAGO realizada en Bahías de Huatulco, Oaxaca, el 18 de noviembre de 2016, quedo instalada la Comisión de Zonas Económicas Especiales, la cual será coordinada por el Gobernador del Estado de Michoacán, Silvano Aureoles Conejo. Dicha comisión presentó la agenda temática y plan de trabajo en la LII Reunión Ordinaria celebrada el 3 de mayo de 2017 en Cuernavaca, Morelos (Tabla 8).

De igual forma en esta agenda temática presentada por la Comisión de ZEE de la CONAGO no se identifica algún eje que este asociado con el ámbito educativo, ya sea para su difusión o para la generación de políticas públicas en dicha materia. Lo que se preserva en ese sentido, es el carácter político y discursivo de la agenda, ya que solo plantea hasta el momento, que es lo que se quiere hacer, pero no se indica el cómo, ni que recursos se utilizarán para la puesta en marcha de los descriptores de cada uno de los ejes, faltando en ese contexto una mayor planeación estratégica, que integre los esquemas de los trabajos presentados.

\subsubsection{Secretaría de Hacienda y Crédito Público.}

La SHCP, a través de la AFDZEE firmó un Acuerdo de Cooperación Técnica con el BM para fortalecer el proceso de desarrollo y creación de las ZEE, en el cual se destacan los siguientes aspectos: 1) Evaluación de la viabilidad de las zonas; 2) Bases institucionales para el Programa de ZEE, que incluye, entre otros temas, marco jurídico y recomendaciones para mejorar la efectividad de la puesta en marcha de las ZEE;. 3) Mejorar la eficiencia distributiva y la productividad a nivel empresarial mediante la reducción de costos administrativos; y 4) Mayores efectos indirectos a la productividad a través de la innovación y el desarrollo de vínculos con proveedores. Este último punto establece que se promoverá la innovación y la transferencia tecnológica, así como la identificación de oportunidades para los proveedores locales identificando sus capacidades para vincularlos con potenciales inversionistas y de esta manera, favorecer el encadenamiento productivo de las pequeñas y medianas empresas (AFDZEE, 2017). 
Tabla 8

Agenda temática de CONAGO en torno a la Comisión de ZEE

\begin{tabular}{|c|c|}
\hline Eje & Descripción \\
\hline $\begin{array}{l}\text { 1. Paquete de incentivos para la } \\
\text { inversión. }\end{array}$ & $\begin{array}{l}\text { Construir al interior de la Comisión un esquema de } \\
\text { incentivos fiscales. Que sea sencillo para fomentar la } \\
\text { inversión y convertir a las ZEE en lugares atractivos para } \\
\text { invertir. }\end{array}$ \\
\hline $\begin{array}{l}\text { 2. Agenda de promoción y atracción } \\
\text { de inversiones. }\end{array}$ & $\begin{array}{l}\text { Conformar agendas de promoción para la inversión } \\
\text { productiva que sume las fortalezas y capacidades } \\
\text { complementarias de la ZEE, con el objetivo de atraer } \\
\text { empresas de gran calado, que detonen sectores } \\
\text { estratégicos, generen empleo y reactiven la economía de } \\
\text { las zonas de influencia. }\end{array}$ \\
\hline 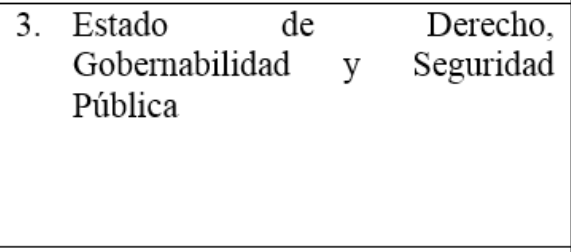 & $\begin{array}{l}\text { La seguridad pública, jurídica y social son condiciones } \\
\text { indispensables para detonar polos de desarrollo. Trabajar } \\
\text { estrechamente con las autoridades en materia de } \\
\text { seguridad y con entre los } 3 \text { órdenes de gobierno, para } \\
\text { generar condiciones propicias a la inversión y la paz } \\
\text { social. }\end{array}$ \\
\hline $\begin{array}{l}\text { Simplificación administrativa } \mathrm{y} \\
\text { mejora regulatoria permanente. }\end{array}$ & $\begin{array}{l}\text { En coordinación con el Gobierno federal habremos de } \\
\text { trabajar con ustedes, los empresarios para facilitar, } \\
\text { agilizar y transparentar trámites y procesos, para la } \\
\text { instalación de empresas, a través de una Ventanilla Única. }\end{array}$ \\
\hline $\begin{array}{l}\text { 5. Plan de Desarrollo Integral de la } \\
\text { ZEE - Ciudades - Areas de } \\
\text { influencia. }\end{array}$ & $\begin{array}{l}\text { La generación de riqueza deberá estar estrechamente } \\
\text { relacionada con la calidad de vida de la población y su } \\
\text { acceso a servicios básicos de salud, educación y } \\
\text { recreación. De ahí la necesidad de estructurar Planes de } \\
\text { Desarrollo Integral para las ZEE, que incluyan líneas de } \\
\text { acción que propicien desarrollo en las áreas de influencia. }\end{array}$ \\
\hline
\end{tabular}

Fuente: tomado de https://www.conago.org.mx/reuniones/2017-05-03.aspx. LII Reunión ordinaria de CONAGO. 3 de mayo de 2017. Cuernavaca, Morelos.

\subsubsection{Banobras.}

El Director General de Banobras, Abraham Zamora Torres (2017), exhortó a potenciales inversionistas a confiar plenamente en el proyecto y decidirse a participar en su desarrollo, ya que está respaldado por un marco legal que garantiza su viabilidad más allá de la presente Administración Federal. Existen oportunidades de inversión privada en obras de infraestructura que se requerirán para la instalación de las ZEE y en las "Áreas de Influencia" de las mismas, en diversos rubros como: transporte y logística, equipamiento, energía, agua e infraestructura urbana. La Banca de Desarrollo está lista para hacer la parte que le corresponde en materia de financiamiento y contribuir a detonar el potencial de las Zonas;

El Fondo Nacional de Infraestructura (FONADIN) brindará apoyos financieros que amplíen la rentabilidad económica de los proyectos, entre los que participarán inversionistas privados. De igual forma, estará presente el respaldo del BM, a través de su Programa MIGA, para facilitar garantías y actuar como aval en las inversiones industriales, y el Banco Interamericano de Desarro- 
1lo (BID), que opera el Programa de Ciudades Emergentes y Sostenibles, para lograr inversiones sustentables en las ciudades donde se ubicarán las Zonas.

\subsubsection{Sector privado.}

De acuerdo con la AFDZEE (2016) el sector privado será protagonista fundamental de las ZEE, existiendo distintas áreas de oportunidad para ellos: antes como API, socios, subcontratistas y realizando estudios; en la operación como empresas ancla, socios, inversionistas, proveedores, generador de nuevas líneas de negocio; en el área de influencia, aprovechando la derrama económica; y en un cluster regional de servicios (profesionales, de consultoría especializada, capacitación, traducción, financieros). Se instalará una ventanilla única para simplificar y agilizar los trámites y regulaciones de las empresas tanto en las ZEE como en el área de influencia, buscando que exista un único contacto, que brinde orientación, simplificación y atención prioritaria, de manera que las empresas brinden información una sola vez y san atendidos de manera física y en una plataforma electrónica.

En ese contexto, para el Presidente del Consejo Coordinador Empresarial (CCE), Juan Pablo Castañón, las ZEE son una vía para equilibrar el desarrollo ya que, indicó, la única manera de generar riqueza es través de la inversión y la generación de oportunidades ( 9 de mayo de 2017)

El 31 de mayo de 2017, las centrales obreras de la Confederación de Trabajadores de México (CTM), la Confederación Revolucionaria de Obreros y Campesinos (CROC) y la Confederación Regional Obrero Mexicana (CROM) firmaron Convenio de Colaboración con la AFDZEE para impulsar la generación de empleos permanentes, el desarrollo industrial, el crecimiento de la productividad del trabajo, e inversiones productivas que impulsen el desarrollo económico de las ZEE, preservando la paz y la estabilidad social.

De acuerdo con Rodolfo Gerardo Guzmán, Secretario General de la CROM (2017) "El Convenio establece un marco de colaboración con las organizaciones que representan los factores de la producción en el trabajo en el que, los representantes de los trabajadores se comprometen a sumar esfuerzos para generar un clima de paz laboral y organizado y así, en un entorno de negocios propicio se puedan atraer inversiones y mejoren las condiciones económicas de los trabajadores y sus familias".

Este tipo de convenios también han sido firmados durante el primer semestre de 2017 con otras instancias como: CMIC, Asociación Nacional de Especialistas fiscales A.C. (ANEFAC), Confederación de Asociaciones de Agentes Aduanales de la República Mexicana A.C. (CAAAREM), La Barra Mexicana de Abogados A,C (BMA), Asociación de Sociedades Financieras de Objeto Múltiple en México A.C. (ASOFOM). La Asociación Nacional de Abogados de Empresas, Colegio de Abogados A.C. (ANADE), Organización Mexicana de Traductores (OMT), Cámara Nacional 
de Empresas de Consultoría (CNEC), Cámara Nacional del Autotransporte de Carga (CANACAR), Cámara Mexicana de la Industria del Transporte Marítimo (CAMEITRAM), Colegio Nacional del Notariado Mexicano A.C, Asociación Mexicana de Empresas de Capital Humano (AMECH), Asociación Mexicana de Agentes Navieros A.C (AMANAC), Asociación Mexicana de Instituciones de Garantías A.C (AMIG) e Instituto Mexicano de Contadores Públicos A.C (IMCP).

\subsubsection{Administradoras portuarias integrales (APIS).}

La ubicación de las cuatro ZEE se encuentra anclada al mismo número de puertos (Lázaro Cárdenas, Salina Cruz, Puerto Chiapas y Coatzacoalcos). Al revisar la captación de recursos de las API's en México, la Secretaría de Comunicaciones y Transportes (SCT, 2017) señaló que las APIS aumentaron sus ingresos de 2015 a 2016, ya que en dicho periodo pasaron de 6,498 millones de pesos a 7,435.3 millones de pesos. Durante 2016, el Puerto de Manzanillo, Colima fue el que recibió la mayor cantidad de ingresos con 1,516.7 millones de pesos, mientras que Lázaro Cárdenas, Michoacán registró 1,268.1 millones de pesos, el Puerto de Veracruz alcanzó 1,480.2 mdp. Los ingresos, según la SCT, corresponden al uso de infraestructura, arrendamientos, cesiones parciales de derechos, y prestaciones de maniobras y servicios (Zanela, 20179).

Como se puede observar, la ZEE de Lázaro Cárdenas, Michoacán se ubica entre los principales puertos mexicanos con respecto a la captación de recursos, lo que puede significar que asuma un liderazgo regional con el resto de las ZEE. Se infiere en ese sentido, que los ingresos obtenidos en los demás puertos nacionales son inferiores a los 1,000 millones de pesos, recursos que son reportados a la federación y que no precisamente se quedan en dichas zonas marítimas. En ese contexto, las APIS pueden contribuir o resarcir el crecimiento puerto-ciudad, pero en realidad, los recursos aportados son limitados para resolver la problemática que históricamente arrastran los puertos en México, específicamente los que se encuentran ubicados en la ZEE

Zanela (2017) cita a Cesar Patricio Reyes Roel (socio consultor de inteligencia marítima), quien señala que integrar financieramente a las API'S al proyecto de las ZEE coadyuvaría con la construcción de la infraestructura de transporte que se requiere para su impulso, por lo menos en lo que respecta al corredor transístmico que une a Salina Cruz con Coatzacoalcos. El tema no puede estar dependiendo del presupuesto que los Diputados den a las ZEE: Los puertos, las API de Coatzacoalcos y Salina Cruz pueden ser parte de este proyecto directamente, pueden ser cedidos al proyecto económicamente, una cosa es que participen y otra cosa es que participen financieramente; que los ingresos que generen esos puertos se queden para las ZEE si el proyecto va a trascender, si no, no tiene ningún caso hacer ese esfuerzo". 


\subsubsection{Gobierno del Estado de Michoacán.}

El 30 de marzo de 2017 el congreso local del Estado de Michoacán aprobó la Ley Estatal de Zonas Económicas del Estado. Durante dicha sesión, el Presidente del Congreso, Pascual Sigala, afirmó que la ZEE representará un "paraíso fiscal" para los empresarios, quienes podrán instalar sus empresas sin mayores trámites legales. De hecho, ya están listos más de 5 mil millones de dólares por parte de empresas que están interesadas en invertir. Mencionó que esto, junto con la construcción del segundo muelle de carga hará que Lázaro Cárdenas se convierta no solo en el puerto marítimo más importante de México sino de todo Latino América.

\subsubsection{Gobierno del Estado de Oaxaca.}

El Gobernador Alejandro Murat afirmó que Oaxaca está listo para las ZEE porque hay gobernabilidad, diálogo y respeto. Recordó que desde hace décadas se ha señalado la ubicación geoestratégica del Itsmo, pero ahora el estado está decidido a escribir una historia de éxito y a sumarse al concierto del desarrollo en México. Algunas de las obras de infraestructura más importante que se han puesto en marcha son: carretera Mitla-Tehuantepec $270 \mathrm{~km}$, que permitirá conectar a Oaxaca con el Istmo estará terminada en 15 meses y que genera una derrama de 3 mil millones de pesos; recientemente se inauguró el Aeropuerto de Ixtepec y de igual manera, se construyen tres libramientos para conectar a los municipios de Matías Romero, Oaxaca con Coatzacoalcos, Veracruz en cuatro horas.

Por su parte, el Gobernador saliente "Gabino Cué Monteagudo destacó que con la participación de las autoridades de los estados que forman parte de esta iniciativa, la implementación de la LFZEE será un detonador de oportunidades para hacer del Sur-Sureste de México, un enclave de progreso, bienestar y prosperidad para el engrandecimiento de la Nación. Refirió que esta administración ha dado pasos importantes para la integración de esta zona a través de la aprobación, realizada en el seno del Fideicomiso para el Desarrollo Logístico del Estado de Oaxaca (FIDELO), de la aportación de casi 780 hectáreas de la zona de las Salinas en este puerto, ubicado en la región del Istmo de Tehuantepec, a fin de que pueda ser ofertada para la inversión. Para este fin se cuenta con 13 hectáreas del denominado "Polígono 14" en donde el Gobierno de Oaxaca invirtió más de 700 millones de pesos, para que quienes vivan en dicha zona cuenten con la infraestructura y servicios necesarios para su bienestar".

\subsubsection{Gobierno del Estado de Chiapas.}

El Congreso del Estado de Chiapas signó en febrero pasado (2017) la Ley de Coordinación para el Establecimiento y Desarrollo de las Zonas Económicas Especiales en el Estado de Chiapas. Las actividades que se podrán realizar para el cumplimiento del objeto de la Ley serán en el sector de la manufactura; agroindustria; procesamiento, transformación y almacenamiento de materias primas 
e insumos; innovación y desarrollo científico y tecnológico; prestación de servicios de soporte a las actividades económicas como servicios logísticos, financieros, informáticos y profesionales, así como la introducción de mercancías para tales efectos.

Por su parte, Mirna Camacho Pedrero, diputada presidenta de la Comisión de Planeación del Congreso del estado, explicó que alineados al Plan Nacional y Estatal de Desarrollo, los proyectos de infraestructura de Chiapas se orientaron en este primer semestre de 2015 a consolidar rutas que converjan en torno a la salida al Pacífico a través del único puerto que tiene la entidad. "El mercado centroamericano tiene un potencial de 60 mil millones de dólares, es decir, su valor comercial neto es el objetivo que debemos atraer con esta iniciativa presidencial a Puerto Chiapas, posicionándonos en el mercado interno de Estados Unidos con productos que van desde el mango ataulfo con denominación de origen, hasta el rambután con una demanda creciente en los últimos años”.

Chiapas está preparado para detonar esta iniciativa: en general tenemos buen clima, riqueza de agua $\mathrm{y}$ variedades de suelos, que constituyen nuestras ventajas comparativas frente a otros estados productores, que podrían complementar el clúster agroindustrial que se visualiza para para los próximos tres años. La eventual puesta en marcha de las ZEE podría ubicar a los estados o municipios generadores o administradores de riquezas, así como regiones de alta marginación y en ellas aplicar mecanismos distintos de cobros o retribución tributaria.

\subsubsection{Gobierno del Estado de Veracruz.}

El 12 de enero de 2017, el Congreso de Veracruz aprobó el dictamen que crea la Ley para el Establecimiento y Desarrollo de Zonas Económicas Especiales del Estado de Veracruz, estableciendo que uno de los objetivos de dicha ley es el de fomentar el desarrollo económico mediante la incentivación de nuevas inversiones y el apoyo a la industria asentada en la entidad, especialmente las microempresas y microindustrias locales. Asimismo, pretende impulsar el potencial productivo y ventajas logísticas de las zonas económicas especiales para superar rezagos que impiden el progreso de Veracruz.

También se establece que la ley tiene la intención de armonizar la legislación local con la federal con la finalidad de coadyuvar con el gobierno federal en la creación de zonas económicas especiales, lo que propician las especiales características del territorio veracruzano y la variedad de productos que ofrecen los diferentes sectores de la actividad económica de la entidad. Será posible incentivar la creación de infraestructura, promover la economía de las regiones en los diferentes sectores productivos y fomentar la generación de empleos, pues se buscará la inclusión en los proyectos de los habitantes de las zonas y áreas aledañas. (León, 2017), 


\subsubsection{Proyectos para las ZEE.}

El diseño es específico para la construcción de proyectos de infraestructura que serán coordinados por una Agencia de Desarrollo para el Crecimiento. Los estímulos fiscales se aplicarán en los proyectos: Corredor industrial interoceánico del Istmo de Tehuantepec, puerto Chiapas y puerto Lázaro Cárdenas. Proyectos adicionales son el Gasoducto transoceánico y Gasoducto Salina Cruz. Las ZEE se asocian también a proyectos de inversión en Pemex y CFE en instalación de ductos, modernización de refinerías en seis entidades y construcción de una más de las plantas de energía eólica: La venta en el Istmo de Tehuantepec en Oaxaca. Cabe recordar que estas inversiones pueden ser realizadas en empresas estatales con inversión privada, a partir de la reforma constitucional en materia energética del 2013 (Correa, 2016:20)

\subsection{Beneficios económicos y fiscales para estados y empresas donde se ubicarán ZEE.}

De acuerdo con información de Presidencia de la República (2016) cada ZEE podrá ofrecer beneficios fiscales directos, tanto a la inversión como al empleo; un régimen aduanero especial; facilidades adicionales para el comercio exterior; un marco regulatorio que agilice la apertura de empresas, además de infraestructura suficiente y competitiva, que asegure el abasto de energía y conectividad logística con el resto del país y los mercados internacionales; financiamiento especial a través de la banca de desarrollo; apoyos a la capacitación laboral y a los procesos de innovación tecnológica, así como una moderna planeación urbana y desarrollo ordenado de viviendas en el área de influencia. Las ZEE son un planteamiento serio, innovador y exigente, que busca adoptar experiencias internacionales exitosas para detonar el desarrollo regional y generar condiciones de igualdad y progreso para millones de mexicanos". Es un proyecto de mediano y largo plazo que trascenderá a la actual administración; en cada zona habrá una ventanilla única para los trámites; se establecerán convenios de coordinación entre los distintos órdenes de gobierno; habrá prácticas acordes con experiencias internacionales, tomando en cuenta que en el mundo hay por lo menos 3 mil 500 ZEE, y la iniciativa incluye mecanismos para la transparencia y la rendición de cuentas en el desarrollo de las ZEE (Sánchez, 2017).

De acuerdo con José Antonio Meade, Secretario de la SHCP (2016), ya se generó un paquete de estímulos fiscales para las cuatro ZEE con el que se descuenta el pago del ISR (empresas y personas físicas): $100 \%$ de la carga tributaria durante 10 años, $50 \%$ durante los subsecuentes 5 años; además se otorgara un crédito a las empresas que se instalen con la mitad de las cuotas patronales del componente de salud del IMSS por 10 años y 25\% de las cuotas por los subsecuentes 5 años. Lo que se produzca en la ZEE causará IVA hasta que deje la ZEE, y mientras se está transformando dentro, no tendrá carga tributaria de valor agregado.

Gutiérrez Candiani, Jefe de la AFDZEE (2016) estima que durante los primeros cinco años 
de operación, las primeras ZEEs generarán más de 63 mil nuevos empleos bien remunerados. Es decir, se generará un incremento de $40 \%$ en los puestos de trabajo registrados en los municipios de Tapachula, Chiapas, Lázaro Cárdenas, Michoacán, Coatzacoalcos, Veracruz y Salina Cruz, Oaxaca. Con esta perspectiva los estados como Chiapas, Michoacán, Veracruz y Oaxaca estarían duplicando sus ritmos de creación de empleo observados en la última década, considerando que se pueden captar en cinco años inversiones por al menos 6 mil mdd, como efecto directo del desarrollo de las Zonas.

Esto representa cerca de la tercera parte de toda la IED que Chiapas, Michoacán, Oaxaca y Veracruz recibieron en la última década. Según estas estimaciones, en los próximos 10 años de operación el monto de las inversiones podría superar los 27 mil millones de dólares. Se trata de detonar la inversión, el empleo y la construcción de encadenamientos productivos, cada vez con mayor valor agregado en centros de desarrollo regional, con una escala cada vez más importante. "Sólo con este tipo de desarrollo se abatirá, de manera perdurable, la pobreza, la desigualdad, la inseguridad y la violencia que aquejan a muchas comunidades

\subsection{Riesgo de inoperatividad de las ZEE.}

En una conferencia ofrecida a industriales de la construcción (18 de septiembre de 2016), Amado Cruz Malpica señaló que la estrategia del desarrollo del sur del país, se ha basado en un esquema predominantemente asistencial; si bien se han implementado programas para abatir carencia básicas, estos no han sido articulados con una política económica que promueva la inversión, el empleo y el crecimiento de la región.

Señaló que si sigue haciéndose lo mismo, los resultados serán los mismos, por ello se requieren nuevas estrategias; y en ese sentido las ZEE representan un esfuerzo para impulsar el desarrollo de regiones rezagadas con un potencial productivo y logístico que no ha sido debidamente aprovechado. También destacó las debilidades de dicho proyecto, como son que la iniciativa privada fungiría como juez y parte, ante la entrega formal de la AFDZEE a la Iniciativa Privada. Además inicia sin consulta a las comunidades de la región, como una imposición derivada de las reformas estructurales.

Destacó la corrupción de autoridades en los tres niveles de gobierno y la presencia del crimen organizado, asentado en la zona. Hay capacidad muy limitada para acciones gubernamentales intersectoriales necesarias y la infraestructura regional es muy débil. En cuanto a las amenazas para el proyecto, el legislador electo mencionó que se atraerá población de otros lugares sin planeación, habría colapso de los servicios públicos, de la seguridad y conflictos con las políticas de las empresas.

Además de que estamos asentados en una zona de alta sismicidad que se está incrementando. Lamentó que el proyecto se base en la explotación de mano de obra barata, además que se pro- 
vocaría una gran depredación del medio ambiente. Insistió en que la transparencia es fundamental, pues hasta el momento el gobierno y el sector empresarial, sólo han mencionado las bondades del proyecto de ZEE, sin referirse a los problemas que causaría a la población y al medio ambiente; aspectos que deberían ventilarse públicamente (Escudero, 2016).

\section{\%. Discusión: variables que explican el éxito o fracaso de una ZEE.}

El BM realizó en 2008 una investigación titulada "Special Economic Zones: performance, lessons learned, and implications for zone development" para examinar 30 años de experiencias en la ZEE, identificando que mientras las zonas han sido efectivas en dirigir el crecimiento económico y objetivos de desarrollo, están no han sido uniformemente exitosas. El triunfo en el Este de Asia y América Latina ha sido difícil de replicar, particularmente en África, y muchas zonas han fracasado. Además, desde el arranque de ZEE en países en desarrollo, la preocupación ha surgido por el impacto en el empleo (en términos de género, nivel salarial y beneficios, derechos de trabajadores y condiciones de trabajo), el medio ambiente y lo relacionado con factores sociales. Para una gran extensión, el destino de la iniciativa de las ZEE se ha determinado desde el exterior, mediante cambios realizados en el establecimiento de políticas de infraestructura, paquetes de incentivos, provisiones y procedimientos burocráticos.

Desde la perspectiva del BM, la experiencia sugiere que el éxito o fracaso de una ZEE está ligada con su política, estructura de incentivos, desempeño y administración de la misma. El uso generoso de paquetes de estímulos, se inclina a otras desventajas, tales como la pobre localización y facilidades insuficientes, lo que implica fuertes gastos de capital y políticas incompetentes, requerimientos rígidos, políticas débiles de empleabilidad, mantenimiento inadecuado, prácticas de promoción en renta subsidiada y otro servicios con procedimientos y controles complicados en estructuras administrativas inadecuadas o en una coordinación endeble entre los desarrolladores privados y el gobierno en la provisión de infraestructura.

La experiencia internacional sugiere que el enfoque recomendado para adoptar el modelo de ZEE debe incorporar los siguientes principios: permitir a las empresas funcionar bajo otros regímenes para localizar dentro de la misma área. El desarrollo de ZEE solamente para empresas es menos preferible, pero es un enfoque aceptable. En la medida que el régimen de ZEE es flexible, este permitirá la atracción de actividades comerciales y manufactureras. Si una ZEE es adecuadamente supervisada, no se requiere un régimen de ZLC separada. Promover el desarrollo de zonas privadas más que públicas, desarrollar una estructura legal e institucional para asegurar la regulación adecuada y la facilitación necesita de disposiciones administrativas efectivas y de un gobierno promotor. 
La práctica apunta a que maximizar los beneficios de las ZEE depende sobre el grado en que están integradas con sus economías huéspedes y en la agenda de reformas al comercio y la inversión. En particular, cuando las zonas se han diseñado para pilotear reformas legales y regulatorias dentro de una política planeada de infraestructura, estas son más probables de alcanzar sus objetivos. Los tomadores de decisiones y los practicantes en las ZEE pueden encontrar consideraciones y lecciones útiles para planear y evaluar sus iniciativas. El resultado final será contar con una infraestructura para zonas de desarrollo futuro para los países anfitriones y para los inversionistas.

Sigler (2014) se basa en los teóricos Chen 1994 y Wei (2000) para identificar el tipo de beneficios que proporciona una ZEE: en la escala nacional, las ventajas directas incluyen IED, generación de empleo y promoción de exportaciones, mientras que los beneficios indirectos incluyen transferencia de tecnología y la facilitación de la liberalización institucional. En la escala local son posibles hacia la fuerza laboral local, el incremento del ingreso y la adquisición de competencias laborales (Papadopolous and Malhotra, 2007). Para Farole (2016) las ZEE se crean para actuar como catalizadoras del comercio, la inversión y del crecimiento económico, ayudan a mejorar la competitividad porque facilitan la transformación económica, dependiendo del país y del momento.

\subsection{Algunos elementos de éxito de las ZEE.}

La política y práctica de ZEE ha estado envuelta todo el tiempo con su ambiente externo. Una tendencia notable en el desarrollo de las ZEE en el mundo en los últimos 15 años ha sido la importancia creciente de las franjas que son desarrolladas y operadas por el capital privado bajo un régimen de propiedad (FIAS-BM, 2008).

A.A. Ortega, et al (2015) señalan que las ZEE alrededor del Este y Sudeste de Asia han sido creadas para alojar corporaciones multinacionales y otras empresas de negocios. Dichos enclaves han pequeña capacidad productiva y de flujos de capital a través de sus ZEE, los cuales son fácilmente expatriados y/o expulsados al exterior, mediante el propio sector bancario, particularmente los servicios internacionales proporcionados por el Canal de Panamá. Maurer and Yu (2011) argumentan que estos sectores han generado crecimiento económico, pero poco empleo o ganancias por impuestos, por lo que dicha estrategia de desarrollo deber ser evaluada como un fracaso.

\subsubsection{Politización y burocracia institucional en la operatividad de las ZEE.}

Geocaniga (2010) retoma el trabajo de Van V. Mejia titulado “Modern Foreing Investment laws of the Philiphinas (2003) para describir las complejidades en instituciones burocráticas y las dificultades que encaran los inversionistas (explica el caso de las ecozonas en Filipinas), destacando mínimos requerimientos de capitalización, la burocracia posee grandes inconvenientes para los inversionistas extranjeros (diferentes reglas para entrar y elegir dónde colocar la inversión). En lugar de 
perder tiempo de una agencia a otra, el inversionista podría gastar mucho más tiempo y esforzarse en mejorar sus operaciones. Se observa, que la burocracia, se da el lujo o la oportunidad de abusar dentro propio sistema. La repetición de los incentivos a los impuestos puede causarle competir contra otros impuestos, por ejemplo: el Income tax holiday bajo el sistema de la Ley PEZA es idéntico al código de inversión OMNIBUS. Aún, dos órganos distintos, el PEZA y el BOI administran estos dos sistemas de incentivos respectivamente (Van V. Mejia, tomado en Geocaniga, 2010: 414).

De acuerdo con Jao y Leung (1986) La burocracia de las ZEE se presenta en términos de una estructura politizada. Por ejemplo, en Shenzhen ${ }^{7}$ la posición de mayor jerarquía en el gobierno estaba ocupada por los líderes del partido de mayor rango. La estructura de la administración estatal es similar a la de los comités del partido, lo que asegura el monitoreo de las operaciones del estado, así como la implementación de las políticas burocráticas. No obstante a que cada ZEE tiene su jurisdicción, frecuentemente los miembros del partido intervienen en las relaciones de Estado de Zhuhai. Los oficiales de dos respectivos sitios frecuentemente se ignoran en tiempos de confrontación, identificándose lo siguiente:

La estructura de gobierno bajo el sistema de dos niveles en Shantou crea procedimientos complicados. Para eliminar la ineficiencia causada por el sistema sugieren que la autoridad debe centralizarse bajo la administración de dicho gobierno; algunas unidades de producción de empresas propiedad del estado han empezado a contratar o asegurar a sus administradores mediante un sistema electivo; un forma efectiva para para prevenir la intervención política es expresar quejas por la visita de un líder importante de Beijing o ir a Beijing para quejarse; el diseño de guías y reglas para definir la extensión de la responsabilidad de un administrador: la autoridad permite la eliminación de no profesionales o titulares políticos y proteger a un administrador de removerlo por un razón política; el uso de medios para combatir la interrupción política desde los cuadros del partido es también un canal efectivo (Jao y Leung, 1986: 108-111)

Desde la visión internacional, de acuerdo con González (2003) al inicio del régimen de IED en China existieron algunas limitaciones para determinadas áreas, como son: transferencia tecnológica, sectores estratégicos, servicios sociales, asistenciales y financieros, control de cambios. Tales limitaciones se encontraban en los ámbitos de lo jurídico, de acceso a mercados, de propiedad, requerimiento de capital, control de cambio externo. Las restricciones permanecieron hasta finales de la década de 1990. Es importante considerar que las medidas de promoción e incentivos a la IED, han sido cuestionadas seriamente por algunos países que consideran a estas como medidas de comercio desleal, ya que se dirigen a las zonas donde se asientan, principalmente las empresas exportadoras (González, 2003:192-193)

7 Los autores advierten que lo mismo ocurre en las ZEE de en Zhuhai, Shantou, y Xiamen 
6.2.3. Conflicto de intereses entre el sector inmobiliario y las áreas rurales.

Desde el contexto local, las ZEE pueden asumir un costo no muy favorable. Por ejemplo, el 6 de agosto de 2011, El Diario Caixin Newspaper de China reportó que oficiales locales del país solicitaron ilegalmente 267 hectáreas para ofrecer espacios a desarrolladores inmobiliarios en Hebei (Shen and Yishi, 2011). Los agricultores fueron amenazados y sus cosechas destruidas cuando se resistían. Tres meses después, el South China Morning Post escribió sobre disturbios en la Provincia de Guangdong por la adquisición de 323.7 hectáreas por el gobierno local en orden de construir un parque industrial en un área residencial (Chi-yuk and Pinghui, 2011). Un total de 12 mil agricultores residentes reclamaron haber sido compensados pobremente. Estos dos casos son solo ejemplos de innumerables acontecimientos similares, los cuales generalmente preludian la construcción de ZEE en China.

En India, los agricultores han luchado contra la adquisición de tierra en los límites de las ZEE. Los granjeros de Raigard protestaron contra la compra de suelo por parte de Industrias Reliance desde 2006 y los de Barnala se resistieron contra la ZEE Trident en Punjab. Sin embargo, el peor caso fue el de las protestas en 2007 contra el proyecto de ZEE de Nandigram en Bengala del Oeste, el cual amenazó la subsistencia de 30 villas. Los pobladores fueron asesinados y muchas mujeres violadas durante las protestas, identificándose la existencia de lagunas en la adquisición de tierras legales en las que se pretendía instalar ZEE (Dohrmann, 2008, p. 76).

\section{Conclusiones.}

A un año de haberse puesto en marcha de la LZEE en 2016, el gobierno mexicano está apostando a la conformación de un discurso oficial que busca alentar a la población de que existen acciones públicas para buscar contrarrestar las grandes desigualdades históricas regionales de la nación.

En ese contexto, lo que se percibe es que los alcances de dicha legislación son limitados con respecto a la realidad económica y social que enfrenta el Suroeste mexicano. Se observa un claro mensaje de que la iniciativa privada será beneficiada con incentivos fiscales y económicos, como la eliminación o descuentos considerables del ISR e IVA durante los primeros 10 años de instalación. Sin embargo, no se tiene claro cómo se resolverán gradualmente las necesidades de la región, toda vez que la iniciativa privada está participando como juez y parte del proceso, esto es algo que no podría asegurar la transparencia en el manejo y administración de los recursos públicos.

Se infiere que por cada millón de dólares invertido se generará un empleo en los primeros cinco años de implementación de las ZEE ¿Qué tipo de empleo serán? Si es mucho o poco, lo que se requiere es entonces contar con capital humano que aproveche las potencialidades y el desarrollo de competencias profesionales en las empresas que se formalicen y los sectores que se desarrollen. 
Contrario a esas necesidades, la región donde se ubicarán las cuatro ZEE continúa presentando al menos desde hace medio siglo, el índice de marginación más alto del país, lo que traduce en un magro desempeño de indicadores económicos y sociales. El que permanezca con altos porcentajes de población indígena y rural y baja participación en el PIB nacional, PIB per cápita, atracción de IED, ingreso corriente, lo conducen directamente a que los niveles de pobreza, pobreza extrema y CG sean altos, al igual que un débil comportamiento del IDH, alta migración y repatriación, así como dependencia de remesas unilaterales enviadas por los mexicanos radicados en Estados Unidos.

Se habla entonces de una región marginada, pobre y económicamente dependiente. Dicha situación no se explica cómo se resolverá con la puesta en marcha de la Ley de ZEE. Luego entonces, lo que se requiere fomentar es un programa ambicioso para atenuar el rezago educativo y las brechas de ingreso, con el objeto de asegurar el capital humano y las condiciones de competitividad (infraestructura de transporte y facilidades de transacción) adecuadas para que la población esté preparada, considerando las exigencias que tendrán las empresas que se instalarán.

Por el poco tiempo que se decretó la Ley de ZEE (2016), aún no se observan los resultados de la acción de gobierno para implementar las ZEE. La normatividad que existe hasta ahora (creación de Comisión intersecretarial y la AFDZEE) es general. Hay una clara adaptación de los propósitos que definen el actuar de las principales ZEE en el mundo, particularmente las que se encuentran ubicadas en el Continente Asiático. Casos de éxito y fracaso como los que ocurren en China, Corea de Sur, India y Filipinas, son un claro ejemplo de que hay evidencia de cómo actuar para una mejor posibilidad de éxito.

Actualmente los esfuerzos han sido encaminados a la difusión y los beneficios que se generarán con la instalación de ZEE. Se identifica una fuerte presencia de la AFDZEE, de la SHCP, Banobras, la iniciativa privada, CONAGO, así como los gobiernos de los cuatro estados participantes. Lo anterior, resulta favorable, debido a que se está buscando acrecentar la llegada de capitales nacionales y externos.

La discusión en este texto es si lo beneficios fiscales incidirán en la creación de buenos empleos y en otorgamiento de salarios bien remunerados. En ese punto es donde se refleja el bajo rendimiento de las ZEE, ya que la realidad no se presenta así. La IED obtendrá su nivel de ganancia, pero redituará poco en la población local. En ese contexto, el riesgo de alcanzar resultados positivos permanece en duda, particularmente porque no existen condiciones de competitividad ni estrategias a la par de como los gobiernos de los estados actuarán en consecuencia.

Finalmente, en el ámbito de la discusión, se tiene claro porque una ZEE alcanza el éxito o porque fracasa. Si la AFDZEE alcanza a magnificar correctamente el diagnóstico estará en posibilidades de establecer pasos concretos para definir qué acciones se seguirán para operar paralelamente los rezagos económicos y sociales. 


\section{Bibliografía y referencias documentales}

Arteaga Ortiz, Jesús, Ferrer Delgado, Pedro, Miranda Martel Maria y Riveras Jorge (2016). Estudio y análisis de Zonas Económicas Especiales. Propuestas de mejora para las Zonas Francas españolas actuales. Revista Empresa y Humanismo Vol XIX, No. 2, ISSN 1139-7608. España: Universidad de Navarra (pag 7-50).

Autoridad Federal para el Desarrollo de las Zonas Económicas Especiales (2017). Firma de Convenios de Colaboración con el Sector Obrero. México, recuperado el 31 de mayo de 2017 enhttp://www.gob. $\mathrm{mx} /$ zee/articulos/firma-de-convenios-de-colaboracion-con-el-sector-obrero?idiom=es

Autoridad Federal para el Desarrollo de las Zonas Económicas Especiales (2017). El sector privado y las zonas económicas especiales. México, recuperado en http://www.gob.mx/zee/articulos/el-sectorprivado-y-las-zonas-economicas-especiales?idiom=es (publicado el 9 de enero de 2017)

Autoridad Federal para el Desarrollo de las Zonas Económicas Especiales (2017). La importancia de la ventanilla única en las zonas económicas especiales. México, recuperado en http://www.gob.mx/ zee/articulos/la-importancia-de-la-ventanilla-unica?idiom=es (publicado el 9 de enero de 2017)

Autoridad Federal para el Desarrollo de las Zonas Económicas Especiales (2017). ¿En

qué se distinguen las ZEE en México de otras zonas en el mundo?. México, recuperado en http://www.gob. $\mathrm{mx} / \mathrm{zee} /$ articulos/hahjs?idiom=es ((publicado el 9 de enero de 2017)

http://www.gob.mx/zee/articulos/hahjs?idiom=es

Autoridad Federal para el Desarrollo de las Zonas Económicas Especiales (2017). IE Singapore y AFDZEE firman Memorando de Mutuo Entendimiento. México: Boletín 02 de la AFDZEE, recuperado el 27 de abril de 2017 en http://www.gob.mx/zee/prensa/boletin-06-ie-singapore-y-afdzee-firmanmemorando-de-mutuo-entendimiento

Autoridad Federal para el Desarrollo de las Zonas Económicas Especiales (2017). Banco Mundial y SHCP Suscriben acuerdo de Cooperación Técnica para fortalecer a las ZEE. México, recuperado el 22 de mayo de 2017 en http://www.gob.mx/zee/articulos/banco-mundial-y-shcp-suscriben-acuerdo-decooperacion-tecnica-para-fortalecer-a-las-zee?idiom=es

Banobras (2017). Banobras y BID trabajan conjuntamente para impulsar sostenibilidad en ciudades mexicanas. México en

https://www.gob.mx/banobras/articulos/banobras-y-bid-trabajan-conjuntamente-para-impulsar-sostenibilidad-en-ciudades-mexicanas-85482?idiom=es

Banobras (2016). Exhorta Abraham Zamora a empresarios a invertir en las zonas económicas especiales. México: Boletín informativo No. 19, recuperado el 25 de octubre de 2016 en http://www.gob.mx/ cms/uploads/attachment/file/158458/Exhorta_Abraham_Zamora_a_empresarios_a_invertir_en_ las_Zonas_Econ_micas_Especiales.pdf

Barba, Guillermo (2014). Elefantes blancos, el riesgo de las zonas económicas especiales mexicanas. Red Forbes. México: recuperado en http://www.forbes.com.mx/elefantes-blancos-el-riesgo-de-laszonaseconomicas-especiales-mexicanas/\#gs.x6G5vGU

Bravo Calderón, Arturo (2016). Las zonas económicas especiales y su impacto en la sostenibilidad de México. Ecoosfera, por México sostenible. México: recuperado en http://ecoosfera.com/2016/11/ las-zonas-economicas-especiales-y-su-impacto-en-la-sostenibilidad-de-mexico/

Cámara de Diputados del H. Congreso de la Unión (LXII Legislatura) (2016). Ley Federal de Zonas Económicas Especiales. México. Recuperado en http://www.diputados.gob.mx/LeyesBiblio/pdf/ LFZEE.pdf

Centro de Estudios de las Finanzas Públicas (2016). Indicadores socioeconómicos de entidades federativas del sur y sureste consideradas por la Ley Federal de las Zonas Económicas Especiales (ZEE) en México. México: Cámara de Diputados de la LXIII Legislatura. Julio 2016

http://www.cefp.gob.mx/publicaciones/presentaciones/2016/precefp0062016.pdf

Chu, David H.Y y Wong, Kwan-Yiu (1985). Modertization in China, the case of the Shenzhen Special Economic Zones. New York: Oxford University Press. 
Ciudadanía express (2016). Itsmo de Tehuantepec, polo estratégico para invertir en ZEE: Gabino Cue. México, recuperado el 15 de noviembre de 2016 en http://ciudadania-express.com/2016/11/15/ istmo-de-tehuantepec-polo-estrategico-para-invertir-en-zee-gabino-cue/

Comisión Nacional para el Desarrollo de los Pueblos Indígenas (2016). Fichas de información básica de la población indígena 2015. México: Presidencia de la República: recuperado el 11 de julio de 2016, en http://www.gob.mx/cdi/articulos/fichas-de-informacion-basica-de-la-poblacion-indigena2015? idiom=es.

Conferencia Nacional de Gobernadores (2016). Acuerdo 25 de la LI Reunión de la Conferencia Nacional de Gobernadores. México, recuperado el 18 de noviembre de 2016, en https://www.conago.org.mx/ reuniones/Acuerdo-Detallado.aspx? $\mathrm{IdR}=227 \& \mathrm{Num}=35$

Consejo Nacional de Población (CONAPO) (2017). Índice de marginación por entidad federativa y municipio 2015. México, recuperado en http://www.gob.mx/conapo/documentos/indice-de-marginacion-porentidad-federativa-y-municipio-2015

Consejo Nacional de Evaluación (Coneval) (2017). Medición de la pobreza en México. México, recuperado en http://www.coneval.org.mx/Paginas/principal.aspx

Correa López, Gabriela (2016). México, Corea y China: entre lo bilateral y lo estratégico. Portes: Revista Mexicana de Estudios sobre la Cuenca del Pacífico. Tercera época, vol 9, no. 19. PP 7-38. ISSN $1870-680$

Cowaloosur, Honita (2013). Land grab in new garb: Chinese special economic zones in Africa The case of Mauritiu. University of St Andrews, Fife, UK African Identities, 2014 Vol. 12, No. 1, 94-109, http:// dx.doi.org/10.1080/14725843.2013.868674. Routledge

Cruz Malpica, Amado (2016). Riesgos podrían imposibilitar las ZEE. México. Recuperado en http:// imagendelgolfo.mx/resumen.php?id=41149388. Boletín de prensa redactado por Heder López Cabrera de la Agencia Imagen del Golfo

El Economista (2016). Invitan a consultores a sumarse a las ZEE. México, recuperado el 10 de noviembre de 2016, en http://eleconomista.com.mx/estados/2016/11/10/invitan-consultores-sumarse-las-zee.

Farole, Thomas (2011). "Special Economic Zones in Africa: Comparing performance and Learning From Global. The World Bank:

Florida, R. (1995). Toward the learning. Futures. Vol. 27, No. 5, pp. 527-536, 1995 Elseviet Science Ltd Printed in Great Britain. https://www.creativeclass.com/rfcgdb/articles/1995-Futures-Toward_the_ Learning_Region.pdf.

Washingtonhttps://openknowledge.worldbank.org/bitstream/handle/10986/2268/600590PUB0ID181onomic09780821386385.pdf; sequence $=1$

Escudero Luis, Margarito (2016). Zona económica especial, la esperanza que no llega. México: El Heraldo de Coatzacoalcos. En

http://heraldodecoatzacoalcos.com.mx/estado/coatzacoalcos/39526-zona-economica-especial-la-esperanza-que-no-llega.html

Diario Oficial de la Federación (2016). Decreto por el que se crea la autoridad federal de las ZEE. México. Presidencia de la República, recuperado el 30 de junio de 2016 en http://www.gob.mx/cms/uploads/ attachment/file/182244/Decreto_AFDZEE.pdf .

Geocaniga, Rommer T. (2010). An analysis of the withdrawal of tax incentives in Special Economic Zones and its Lesal Implications. Ateneo Law Journal. Sep2010, Vol. 55 Issue 2, p409-446. 38p. Manila University Scholl ok Low.

Gobierno del Estado de Oaxaca (2017). Aprueba Congreso de Michoacán Ley de Zonas Económicas Especiales. México, recuperado en

http://www.unotv.com/noticias/estados/michoacan/detalle/aprueba-congreso-michoacan-ley-zonas-economicas-especiales-707783/

Gobierno de México (2013). Plan Nacional de Desarrollo 2013-2018. México: Presidencia de la República

González García, Juan (2003). China: Reforma económica y apertura externa. Transformación, efectos y desafios, un enfoque neoinstitucional. México: Grupo editorial Miguel Ángel Porrua, Universidad de Colima, El Colegio de México y LVIII Legislatura del Senado de la República. 
Gutiérrez Candiani, Gerardo (2017). Las ZEE generarán bienestar en el Sureste. México: AFDZEE. Recuperado el 22 de mayo de 2017 (http://www.gob.mx/zee/articulos/las-zee-generaran-bienestaren-el-sureste?idiom $=\mathrm{es})$

Gutiérrez Candiani, Gerardo (2017). El jefe de la AFDZEE participó en el Tercer Foro de Consulta Infraestructura de la CMIC. México: Boletín 08 de la AFDZEE. Recuperado el 9 de mayo de 2017. En http://www.gob.mx/zee/prensa/boletin-08-el-jefe-de-la-afdzee-participo-en-el-tercer-foto-deconsulta-infraestructura-de-la-cmic.

INEGI (2015). Referencias geográficas y extensión territorial de México. México: recuperado en http:// www.inegi.org.mx/inegi/SPC/doc/internet/1-GeografiaDeMexico/MAN_REFGEOG_EXTTERR_ VS_ENERO_30_2088.pdf

Jao Y.C and Leung C.K. (editors) (1986). China's Special Economics Zones: politics, problems and prospects. New Yorj: Oxford University Press

Li, Juan José; Reyes, Alejandra; Bermúdez, Juan y Mendoza, Alfonso (2016). Anuario de migración y remesas (2016). México: Fundación BBA Bancomer (BBA Research) y CONAPO. México, recuperado el 6 de marzo de 2017 en: http://www.gob.mx/cms/uploads/attachment/file/109457/ Anuario_Migracion_y_Remesas_2016.pdf

Luna, Carmen (2017). La inversión en zonas económicas especiales llega en marzo. México, recuperado el 2 de febrero de 2017 en http://expansion.mx/economia/2017/02/15/inversion-en-zonas-economicasespeciales-llega-en-marzo.

Makabenta, Maria Peregrina (2002). FDI Localization and Special Economics Zones in the Philippines. The Applied Regional Science Conference (ARSC) / Blackwell Publishing Ltd. 2002. Published by Blackwell Publishing. RURDS Vol. 14, No. 1, March 2002

Ortega Arnisson Andre, Astrid E. Marie Johanna and H. Hermida Maria Celeste (2015). Mega-regions in the Philippines: Accounting for special economics zones and global-local dynamics. University of Philippines: ELSEVIR. Cities 48 (2015) 130-139. www.elsevier.com/locate/cities

Pakdeenurit, Patcharee; Suthikarnnarunai, Nanthiy and Rattanawong, Wanchai (2014), "Special Economic Zone: Facts, Roles, and Opportunities of In vestment",Proceedings of the International Multi Conference of Engineers and Computer Scientists, Hong Kong. Artega

Presidencia de la República (acciones y programas) (2016). Las zonas económicas especiales en México. México: recuperado el 17 de noviembre de 2014 en http://www.gob.mx/presidencia/acciones-yprogramas/zonas-economicas-especiales-15774?idiom=es).

Presidencia de la República (2016). Marco jurídico de la Comisión Intersecretarial de ZEE. México, recuperado el 8 de febrero de 2017 en http://www.gob.mx/zee/documentos/marco-juridico-de-lacomision-intersecretarial-de-zee

Perroux, Francoise (1964). La economía del siglo XX, o p. cit., 1964, p. 140.

Ruiz Funes, Mariano (2016). Zonas económicas especiales, bloques y e inversiones. México: recuperado en http://www.elfinanciero.com.mx/opinion/zonas-economicas-especiales-bloqueos-e-inversiones. html

Sánchez, Enrique (2015). Peña Nieto firma iniciativa de Zonas Económicas Especiales. México, recuperado el 30 de septiembre de 2015 en http://www.excelsior.com.mx/nacional/2015/09/30/1048432.

Sigler, Thomas J. (2014). Panama's Special Economic Zones: Balancing Growth and Development. Bulletin of Latin American Research, Vol. 33, No. 1, pp. 1-15, 2014. University of Queensland, Australia.

Tarverner, James (2007). El desarrollo económico en China y la influencia de las zonas económicas especiales". IX Reunión de Economía Mundial, Madrid.

The World Bank Group (2008), Special Economic Zones, Performance, Lessons Learned, and Implications for Zones Development, Washington. http://documents.worldbank.org/curated/ en/343901468330977533/pdf/458690WP0Box331s0April200801PUBLIC1.pdf

Van V. Mejia. (2003). The Modern foreing investemt low of Philippines. 17 TEMP, INT'L And Company L.J 467.

Zamora Torres, Abraham (2017). Zonas Económicas Especiales, instrumentos de desarrollo regional. México: Banobras: https://www.gob.mx/banobras/articulos/zonas-economicas-especiales-instrumentos-dedesarrollo-regional?idiom $=\mathrm{es}$ ) 
Las zonas económicas especiales en el suroeste de México y el desarrollo regional • José Manuel Orozco Plascencia

Zanela, Luis Alberto (2017). Ingresos de las APIS consolidarían zonas económicas especiales. México, recuperado el 13 de febrero de 2017 en

http://t21.com.mx/maritimo/2017/02/13/ingresos-las-api-consolidarian-zonas-economicas-especiales\#comment-72403 (13 feb de 2017)

Zanela, Luis Alberto (2017). Puertos duplican crecimiento en 2016. México, recuperado el 6 de marzo de 2017 en http://t21.com.mx/maritimo/2017/03/06/puertos-duplican-crecimiento-ingresos-2016. 
Números anteriores:

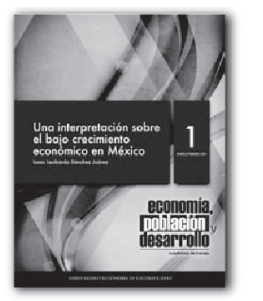

Economía, población y desarrollo.
Cuadernos de trabajo №1

Enero-Febrero 2011
Una interpretación sobre el bajo

crecimiento economico en México
Isaac Leobardo Sánchez Juárez

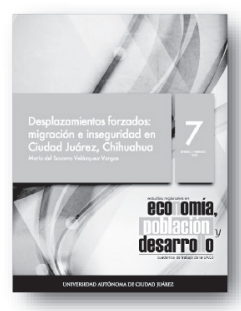

Economia, población y desarroll

Cuadernos de trabajo $\mathrm{N}$ -
Encro-Fcbrcro 2012

Desplazamientos forzados
migración e inseguridad

Ciudad Juárez, Chihuahua
Maria del Socorro Velázquez Varga

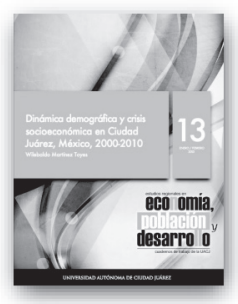

Economiá, población y desarrollo

de trabajo $N$

Dinámica demográ́fica y crisis
socieconómica en Ciudad Juáre Mexico, 2000-2010



Economía, población y desarroll Enero - Febrero 2014 Bienestar, automóvil y motorización
Pablo Martín Urbano y Miosánchez Gutiérrez

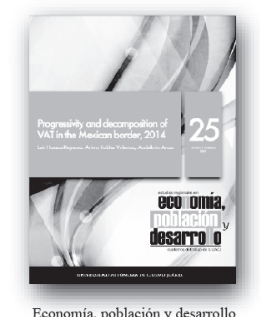

Cuadernos de trabajo No $_{0}$
Conomia,

Encro - Febrero 2015

Progressivity and decomposition of
VAT in the Mexican border, 2014 Abdelkim Araar

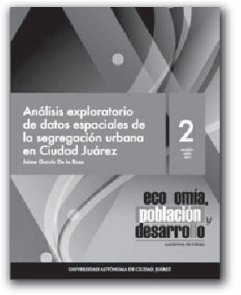

Economía, población y desarrollo.
Cuadernos de trabajo № 2

Marzo-Abril 2011

espaciales de la segregacón

Jaime Garcia De la Rosa

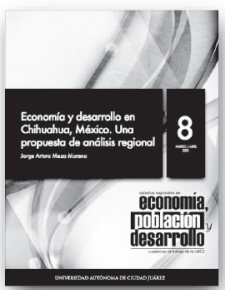

Economia, población y desarrollo

Cuadernos de trabajo №7

Economía y desarrollo en

propuesta de análisis regiona

Jorge Arturo Meza Moreno

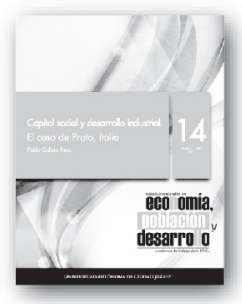

Economía, población y desarrollo

Marzo - Abri1 2013

Capital social y desarrollo

Pablo Galaso Reca

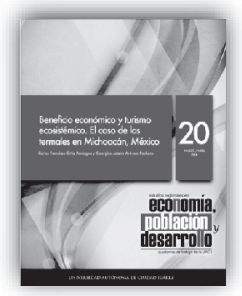

Economia, población y desarrollo

Marzo - Abril 2014

Beneficio económico y turismo

enico. El caso de las ter
en Michoacán, Mésico

arlos Franciseo Ortiz Paniagu

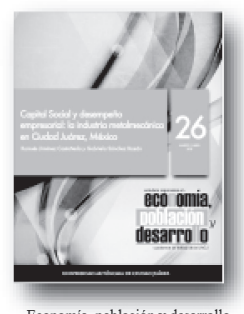

Economía, población y desarrollo

Cuadernos de trabajo № 26
Marzo - Abril 2015

Capital Social y desempeño empresa
la industria metalmecánica en

a industria metalmecánica en
Ciudad Juárez, México

Ramsés Jiménez Castañeda y
Gabriela Sáncez Bazán
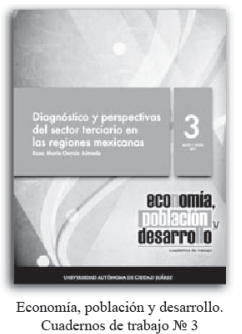

Diagnóstico y perspectivivas

regiones mexicanas
rosa Mária Garcia Almad

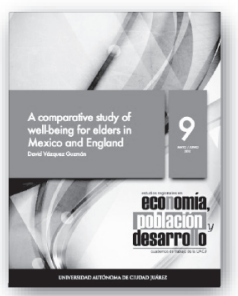

Economia, población y desarrollo

Cuadernos de trabajo № 9
Mayo - Junio 2012

A comparative study of

Mexico and England
David Vázquez Guzmán

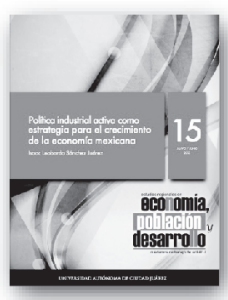

Economia, población y desarroll

Madernos de trabajo
Mayo - Junio 2013

Politica ind ustrial activa como

strategia para el crecimiento

Isaac Lcobardo Ś́nexicana
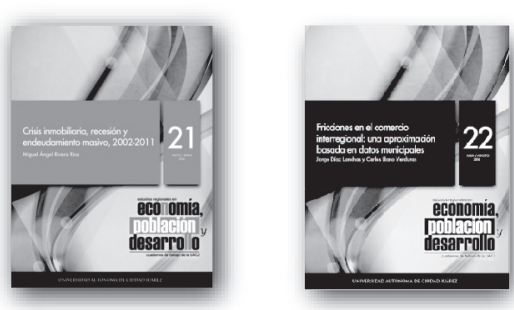

Economia, población y desarrollo

Cuademos de trabajo
Mayo - Junio 2014

Crisis inmobiliaria, recesión y
adeudamiento masivo, $2002-2011$

Miguel Ángel Rivera Rios

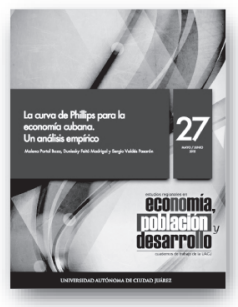

Economia, población y desarrollo

Cuadernos de trabajo № 27

a curva de Phillips para

economía cubana.

Malena Portal Boza, Duniesky Feitó

Economía, población y desarrollo.
Cuadernos de trabsio

julio-Agosto 201

Los indices IDH y FGT en la

mera década del siglo XX

Economía, población y decarrollo

Cuadernos de trabajo №
Julio - Agosto 2012

Political competition and the

edistribution in a federation

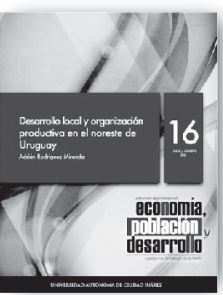

Economía, población y desarrollo

Cuadernos de trabajo №
Julio - Agosto 2013

Desarrollo local y organización
productiva en el noroeste de Urugu

Economía, población y desarrollo

Julio - Agosto 2014

Ficciones en el comercio

basada en datos municipales
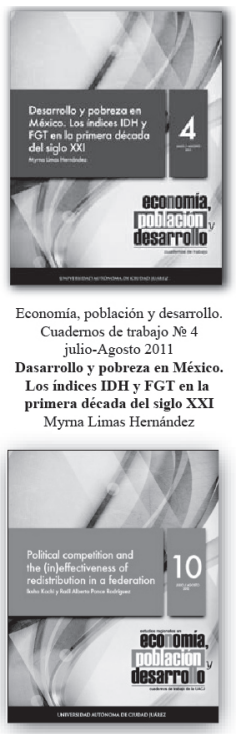

Jorge Diaz Lanchas y Carlos Llano Verduras
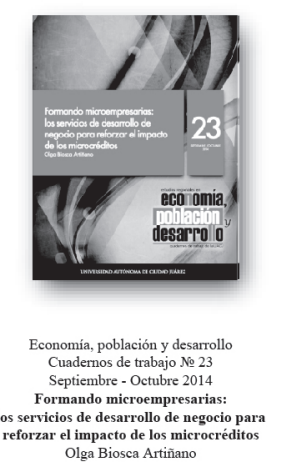

Cuadernos de trabajo № 24

El crecimiento de las regiones

el paradigma del desarrollo

divergente. Un marco térico
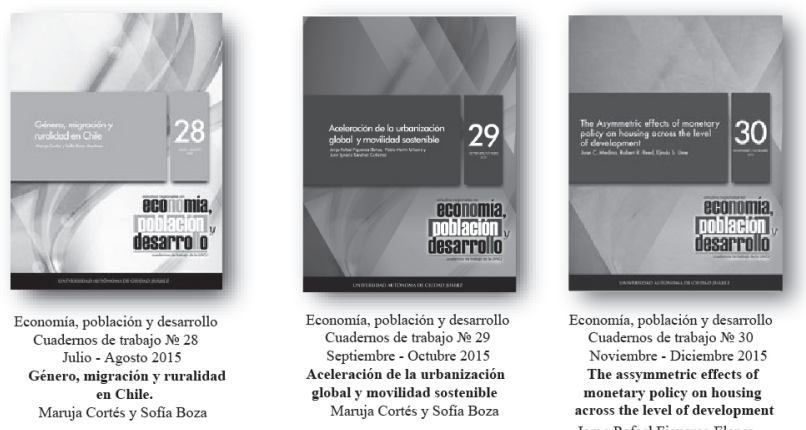

conomía, población y desarrol

Cuadernos de trabajo № 30

The assymmetric effects of

monetary policy on housing

Jorge Rafael Figueroa Elenes,

Juan Ignacio Sánchez Gutiérrez 
Números anteriores:
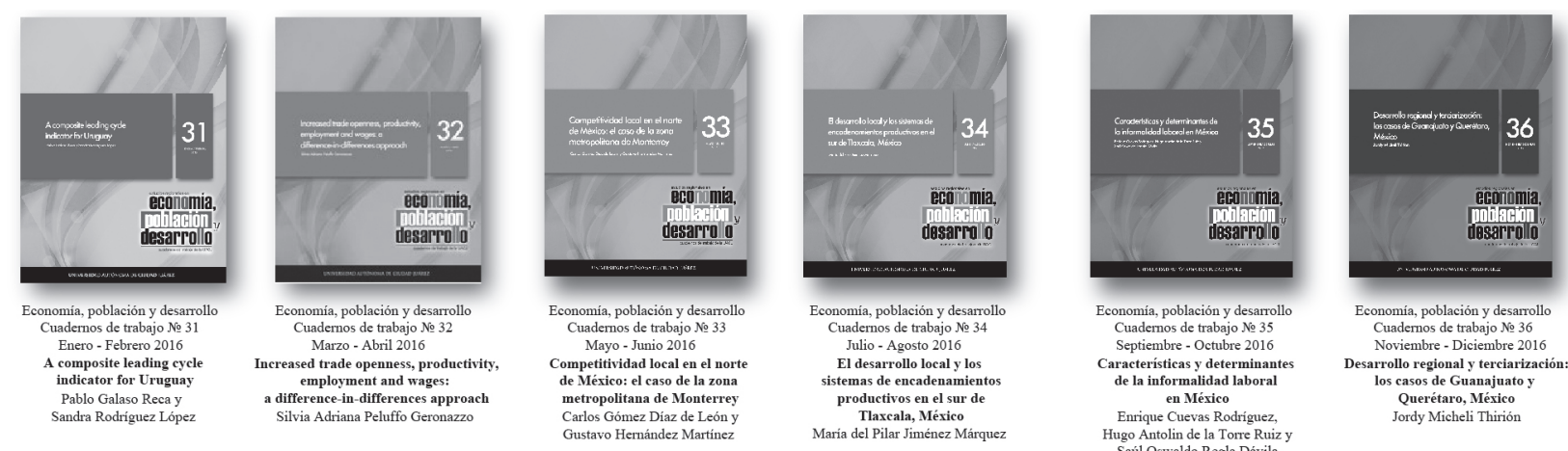

conomía, población y desarrollo Septiembre - Octubre 2016

Caracteristicas $y$ determinantes
de la informalidad laboral

de la informalidad laboral
en México

Enrique Cucvas Rodríguez,

Gustavo Hernández Martinez

Maria del Pilar Jiménez Márquez
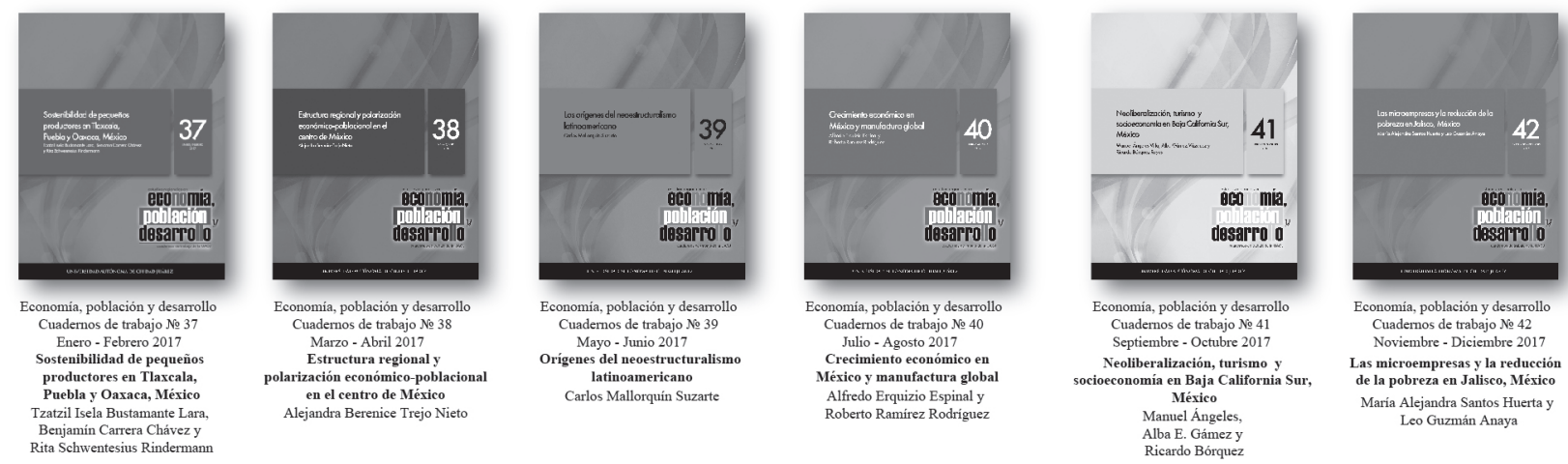

Cuadernos de trabajo № 42 Noviembre - Diciembre 2017

Enero - Febrero 2017

productores en Thaxcala,

zzatzil Iscla Bustamante Lara, Alcjandra Berenice Trejo Nieto

Alfredo Erquizio Espinal y
Roberto Ramirez Rodríguez

Las microempresas y la reducción
de la pobreza en Jallisco, México

Maria Alcjandra Santos Huctta y Leo Guzmann Anaya 


\section{$\rightarrow$ Normas Editoriales}

\section{Para el documento general:}

Tipo de letra: Times New Roman.

Tamaño: 11 puntos.

Interlineado: 1.5 espacios.

Títulos y subtítulos:

El texto principal en 11 puntos. Títulos 12 puntos (en resaltado). Subtítulos 11 puntos. Cada título y subtítulo deberá numerarse bajo el siguiente orden: $1,1.1,2,2.1,2.2 \ldots$

La extensión máxima de los cuadernos de trabajo será de 40 cuartillas.

La primera vez que se emplee una sigla en el texto se especificará primero su equivalencia completa y después la sigla.

\section{Hoja de presentación:}

Título:

14 puntos, centrado, resaltado.

Nombre de autor(es):

12 puntos

Resumen y abstract:

Debe incluir resumen en español y abstract (diez puntos), no mayor a 250 palabras

Palabras clave:

Incluir entre tres y cinco palabras clave, en español e inglés

Referencia del autor o autores:

Institución de adscripción, grado académico y líneas-grupos de investigación que desarrolla y a los que pertenece.

\section{Sistema de referencia de citas:}

Harvard-APA

Las citas bibliográficas en el texto deberán incluir entre paréntesis sólo el apellido del autor, la fecha de publicación y el número de página; por ejemplo: (Quilodrán, 2001: 33).

\section{Notación en sección de bibliografía y fuentes de información:}

Se deberá incluir al final del texto. Toda referencia deberá estar mencionada en el texto o notas de pie de página.

Cada referencia iniciará con el primer apellido o los apellidos, luego el nombre del autor, y después, entre paréntesis, el año de publicación seguido de un punto. Ejemplos:

Se deberá incluir al final del texto. Toda referencia deberá estar mencionada en el texto o notas de pie de página.

Cada referencia iniciará con el primer apellido o los apellidos, luego el nombre del autor, y después, entre paréntesis, el año de publicación seguido de un punto. Ejemplos:

Artículo:

Ros, Jaime (2008). "La desaceleración del crecimiento económico en México desde 1982”, en Trimestre Económico, vol. 75, núm. 299, pp. 537-560.

Libro:

Villarreal, René (2005). Industrialización, competitividad y desequilibrio externo en México. 
Un enfoque macroindustrial y financiero (1929-2010), México, Fondo de Cultura Económica. Capítulo de libro:

Castillo, Manuel Ángel (2003). "La política de inmigración en México: un breve recuento", en Manuel Ángel Castillo, Alfredo Lattes y Jorge Santibáñez (coords.), Migración y fronteras, Tijuana, El Colegio de la Frontera Norte / Asociación Latinoamericana de Sociología / El Colegio de México, pp. 425-451.

\section{Notas de pie de página:}

Se utilizarán para hacer indicaciones complementarias, aclaraciones o ampliación de una explicación. La notas de pie de página en Times New Roman, 10 puntos.

\section{Tipología de imágenes dentro del texto:}

Cuadro

Gráfica

Diagrama

Mapa

Figura

Todas las imágenes deben ser numeradas y mencionadas dentro del texto. A toda imagen debe incluirse la fuente.

Las indicaciones de la imagen: tipo y número de imagen, título de imagen y fuente se escriben en 10 puntos. En el texto poner como imagen los mapas, figuras, gráficas y diagramas -con el ánimo de no perder el formato realizado por el autor.

\section{Ecuaciones y fórmulas:}

Si se utilizan ecuaciones o fórmulas deberá utilizarse el editor de ecuaciones de Word y numerarse.

\section{Envío de trabajos}

Los trabajos deben ser enviados a la dirección de correo: lgtz@uacj.mx. Con el Dr. Luis Enrique Gutierrez Casas, editor de esta publicación.

La aceptación de cada colaboración dependerá de la evaluación de dos dictaminadores especialistas en la materia que se conservarán en el anonimato, al igual que el autor (autores) para efectos de la misma. 


\section{$\rightarrow$ Editorial Guidelines}

\section{For General Document:}

Font type: Times New Roman.

Size: font size 11 .

Paragraph: 1.5 line spacing.

Titles and subtitles: Main text font size 11. Titles font size 12 (Bold). Subtitles font size 11.

Each title and subtitle should be numbered in the following order: 1, 1.1, 2, 2.1, 2.2...

The maximum length of the workbooks will be 40 pages.

The first time an abbreviation is used in the text will be specified first complete equivalence and then stands.

\section{Front cover:}

Title:

Font size 14, centered, Bold.

Author name(s):

Font size 12.

Abstract:

It should include abstract in Spanish and abstract (font size 10), no more than 250 words.

Keywords:

Include three to five keywords, in Spanish and English.

Reference of author:

Institution of affiliation, academic degree and line-developed by research groups and belonging.

\section{Bibliographical appointment system:}

Harvard-APA

Citations in the text should include between parentheses only the author's name, publication date and page number, for example:

(Quilodrán, 2001: 33).

\section{Notation about Bibliography section and Information fonts:}

Should be included at the end of the text. All references must be mentioned in the text or footnotes page.

Each reference starts with the first name or last name, then the name of the author, and then, in parentheses, the year of publication followed by a period. Examples:

Article:

Ros, Jaime (2008). “La desaceleración del crecimiento económico en México desde 1982”, en Trimestre Económico, vol. 75, núm. 299, pp. 537-560.

Book:

Villarreal, René (2005). Industrialización, competitividad y desequilibrio externo en México. Un enfoque macroindustrial y financiero (1929-2010), México, Fondo de Cultura Económica.

Book chapter:

Castillo, Manuel Ángel (2003). "La política de inmigración en México: un breve recuento”, en Manuel Ángel Castillo, Alfredo Lattes y Jorge Santibáñez (coords.), Migración y fronteras, Tijuana, E1 Colegio de la Frontera Norte / Asociación Latinoamericana de Sociología / El Colegio de México, pp. 425-451. 


\section{Footnotes:}

Must be used to make additional indications, clarification or expansion of an explanation. The footnotes must be in Times New Roman, font size 10.

\section{Image typology inside text:}

Picture

Graph

Diagram

Map

Figure

All images must be numbered and mentioned in the text, should include the source image. The indications of the image: type and number of image, image title and source are written in 10 font size. In the text set as image maps, figures, graphs and charts-with the intention of not losing the formatting by the author.

\section{Equations and Formulae:}

When using equations or formulas should be used in Microsoft Word equation editor and numbered.

\section{Paper sending}

Entries must be sent to the email address: lgtz@uacj.mx. With Dr. Luis Enrique Gutiérrez Casas, editor of this publication.

Acceptance of each collaboration will depend on the evaluation of two examiners skilled in the art to be kept anonymous, like the author(s) for the same purposes. 


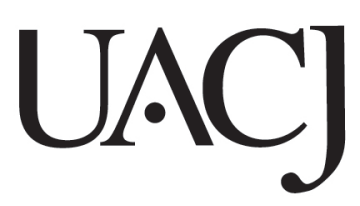

Esta obra se terminó de imprimir en diciembre de 2017

Cd. Juárez, Chihuahua, México.

Tiraje: 120 ejemplares 
Cuadernos de Trabajo de la Universidad Autónoma de Ciudad Juárez, número 43, enero - febrero de 2018

\section{Director y editor}

\section{Dr. Luis Enrique Gutiérrez Casas}

\section{Comité editorial}

Sección internacional

Dra. Sofía Boza Martínez (Universidad de Chile, Chile)

Dra. Olga Biosca Artiñano (Glasgow Caledonian University, Reino Unido)

Dra. Ángeles Sánchez Díez (Universidad Autónoma de Madrid, España)

Dr. Thomas Fullerton Mankin (University of Texas at El Paso, Estados Unidos)

Dr. Adrián Rodríguez Miranda (Universidad de la República, Uruguay)

\section{Sección local}

(Universidad Autónoma de Ciudad Juárez)

Dra. Myrna Limas Hemández

Dra. Ikuho Kochi

Dr. Raúl Alberto Ponce Rodríguez

Dr. Isaac Leobardo Sánchez Juárez

Dr. Héctor Alonso Barajas Bustillos 